\title{
Refined nomic truth approximation by revising models and postulates
}

\author{
Theo A. F. Kuipers ${ }^{1}{ }_{(D}$
}

Received: 12 September 2017 / Accepted: 7 March 2018 / Published online: 19 March 2018

(C) The Author(s) 2018

\begin{abstract}
Assuming that the target of theory oriented empirical science in general and of nomic truth approximation in particular is to characterize the boundary or demarcation between nomic possibilities and nomic impossibilities, I have presented, in my article entitled "Models, postulates, and generalized nomic truth approximation" (Kuipers in Synthese 193(10):3057-3077, 2016. https://doi.org/10.1007/s11229-0150916-9), the 'basic' version of generalized nomic truth approximation, starting from 'two-sided' theories. Its main claim is that nomic truth approximation can perfectly be achieved by combining two prima facie opposing views on theories: (1) the traditional (Popperian) view: theories are (models of) postulates that exclude certain possibilities from being realizable, enabling explanation and prediction and (2) the model view: theories are sets of models that claim to (approximately) represent certain realizable possibilities. Nomic truth approximation, i.e. increasing truth-content and decreasing falsity-content, becomes in this way revising theories by revising their models and/or their postulates in the face of increasing evidence. The basic version of generalized nomic truth approximation is in many respects as simple as possible. Among other things, it does not take into account that one conceptual possibility may be more similar (or closer) to another than a third one (is to that other). However, for example, one theory may include a possibility that is more similar to a wrongly not included possibility than another theory can offer. Similarly, for wrongly not excluded possibilities. In this article it will be shown that such 'refined' considerations can be taken into account by adapted clauses based on a ternary similarity relation between possibilities (structures). This allows again abductive conclusions about refined truth approximation if a theory is persistently more successful in the refined sense than another. It
\end{abstract}

\footnotetext{
Theo A. F. Kuipers

T.A.F.Kuipers@rug.nl

1 University of Groningen, Groningen, The Netherlands
} 
will also be indicated and illustrated that this refined approach enables a specification to the effect that refined truth approximation can be obtained by the method of idealization and subsequent concretization. Finally, the basic and the refined approach will be evaluated with regard to some general principles and objections that have been discussed in the literature.

Keywords Truthlikeness · Verisimilitude · Refined truth approximation · Refined success theorem - Idealization and concretization - Ideal gas model · Van der Waals model $\cdot$ Validity research $\cdot$ Child's play objection

\section{Introduction ${ }^{1}$}

In a recent article, "Models, postulates, and generalized nomic truth approximation"2 (Kuipers 2016), I have presented the 'basic' version of generalized nomic truth approximation, starting from 'two-sided' theories. In my view (Kuipers 2000), the target of theory oriented empirical science in general and of nomic truth approximation in particular is to characterize the boundary or demarcation between nomic possibilities and nomic impossibilities, for example the demarcation between physically possible and impossible states or trajectories of a system or between economically possible and impossible markets. The main claim of the new article is that nomic truth approximation can perfectly be achieved by combining two prima facie opposing views on theories:

1. The traditional (Popperian) view: theories are (sets of models of) postulates that exclude certain possibilities from being realizable, enabling explanation and prediction.

2. The model view: theories are sets of models that claim to (approximately) represent certain realizable possibilities.

Nomic truth approximation, i.e. increasing or otherwise improving truth-content and decreasing or otherwise weakening falsity-content, becomes in this way revising theories by revising their models and/or their postulates in the face of increasing evidence. My pre-2012 work on truth approximation ${ }^{3}$ was restricted to maximal theories, that is, theories in which the models are just all structures satisfying the postulates. Hence, the two-sided approach is a far-reaching generalization.

The basic version of generalized nomic truth approximation is in many respects as simple as possible. The present article deals with the second of (at least) three plausible concretizations of the basic version [in line with such concretizations in Kuipers (2000)]: a quantitative version, a refined version, and a stratified version, based on a (theory-relative) distinction between an observational and an inclusive theoretical

\footnotetext{
1 This introduction is heavily based on another separately published chapter (Kuipers 2017) of a book manuscript of Kuipers, Nomic Truth Approximation Revisited, dealing with another concretization, viz. quantification.

2 Highly inspired by Cevolani et al. (2011).

3 Notably (Kuipers 2000).
} 
level. ${ }^{4}$ The intended refined version in this article is based on an underlying ternary similarity relation, called structurelikeness, enabling to make e.g. one counterexample less dramatic than another, and enabling to deal e.g. with 'idealization \& concretization' of theories.

To present the refined version we will first clarify, in Sect. 2, the main target of nomic truth approximation and the nature of (true and false) two-sided theories and of empirical evidence. Then we will present the crucial definitions of the basic account and the corresponding success theorem. We will not only adapt but also revise the definitions in Kuipers (2000, Chapter 10) of 'refined closer to' and 'refined more successful' between two two-sided theories. Among other things, the 'refined success theorem' will now hold unconditionally, as in the basic case, roughly, 'refined closer to' entails 'refined more successful'. The theorem enables tentative refined nomic truth approximation conclusions by abductive reasoning.

We will present the main refined definitions in two rounds. In Sect. 3 we will start by introducing the notion of structurelikeness, crucial for refinement. Then we introduce the refined definitions in such a way that they are conceptually highly plausible and lead to the refined success theorem. In Sect. 4 we will summarize the main notions in a couple of handsome tables. In Sect. 5 we will focus on the special cases where refinement concerns the transition of an idealization to a concretization. We conclude (Sect. 6) with the evaluation of the refined approach with regard to some general principles and objections that have been discussed in the literature.

\section{Nomic theories, nomic evidence, and the basic account}

\subsection{Nomic theories and nomic evidence}

As stated before, in my view (Kuipers 2000), the target of theory oriented empirical science in general and of nomic truth approximation in particular is to characterize the boundary or demarcation between nomic possibilities and nomic impossibilities. ${ }^{5}$ For this purpose we need to presuppose a set, $\mathrm{U}$, of conceptual possibilities in a given, bounded, context, e.g. the states or trajectories of a system or a type of systems, ${ }^{6}$ that is, the set of structures generated by a descriptive vocabulary, $\mathrm{V}$, in which $\mathrm{U}$ and subsets of U, e.g. X, Y, M, P, R, S, are characterized (cX will indicate the complement of $\mathrm{X}$ ). Let bold $\mathbf{T}$ indicate the unknown subset of $\mathrm{U}$ of nomic possibilities, not (yet) based on $\mathrm{V}$. Hence c $\mathbf{T}$ indicates the subset of nomic impossibilities.

\footnotetext{
${ }^{4}$ In (Kuipers, Nomic Truth Approximation Revisited, book manuscript) the other two concretizations are presented: a quantitative version and a stratified version.

${ }^{5}$ Hence, 'nomic' is used here as a generic term. Moreover, the notion of nomic possibility, and its field specific cases, such as physical possibility, function as basic or primitive ones, with corresponding laws, such as physical laws, as derivative notions.

${ }^{6}$ Hence, $\mathrm{U}$ is not a set of possible worlds in the standard 'there is only one world' sense, but concerns socalled 'small worlds'. They are only mutually exclusive and jointly exhaustive in the same case in the given context, e.g. a system may have several physically possible states, but has only one state at one time. Cf. the space of possible elementary outcomes in probability theory: one experiment has only one elementary outcome.
} 
In these terms, the target of nomic research is identifying, if possible, T's boundary in V-terms, called the nomic truth, for reasons that will become clear soon. For this purpose we design theories with claims. A (two-sided) theory is a tuple $<\mathrm{M}, \mathrm{P}>$ of subsets of $\mathrm{U}$, defined in $\mathrm{V}$-terms, where $\mathrm{M}$ indicates a set of (specified) models and $\mathrm{P}$ indicates the set of models of certain Postulates ( $\mathrm{P}=$ Models (Postulates)). The theory's claims are:

" $\mathrm{M} \subseteq \mathbf{T}$ ", the inclusion claim: all members of $M$ are nomic possibilities.

"T $\subseteq$ P", i.e. "cP $\subseteq$ cT", the exclusion claim: all non-members of $P$ are nomic impossibilities

This combines the two views on theories: representation (or inclusion) and exclusion. The two claims are compatible, making the theory consistent, iff (if and only if) $\mathrm{M} \subseteq \mathrm{P}$, that is, assuming the chosen models satisfy the chosen postulates (i.e., are models of these postulates).

A theory is maximal if $\mathrm{M}=\mathrm{P}$; non-maximal otherwise. My pre-2012 work on truth approximation was restricted to maximal theories, hence we deal now with a farreaching generalization. The definition of two-sided theories leaves formally room for two one-sided extremes: $<\mathrm{M}, \mathrm{U}>$ and $<\emptyset, \mathrm{P}>$, i.e. pure inclusion and pure exclusion theories, respectively, also referred to as the $\mathrm{M}$ - and $\mathrm{P}$-theory constituting theory $<\mathrm{M}$, $\mathrm{P}>$.

A theory $<\mathrm{M}, \mathrm{P}>$ is true if both claims are true, i.e. $\mathrm{M} \subseteq \mathbf{T} \subseteq \mathrm{P}$, false otherwise. It is easy to check that there is at most one true maximal theory, called the true theory or simply the (nomic) truth, resulting from the characterization of $\mathbf{T}$ in $\mathrm{V}$-terms, if it exists. ${ }^{7}$ It will be indicated by $<\mathrm{T}, \mathrm{T}>$, or simply $\mathrm{T}$, i.e. non-bold ' $\mathrm{T}$ '. This $\mathrm{T}$ is more specifically the target of (theory-oriented) research! It is also easy to check that this maximal theory $<\mathrm{T}, \mathrm{T}>=\mathrm{T}$ is the strongest true (two-sided) theory, with claim(s): $\mathrm{T} \subseteq \mathbf{T} \subseteq \mathrm{T}$, i.e. $\mathbf{T}=\mathbf{T}$. The term 'strongest theory' is based on the notion that e.g. the inclusion claim of theory $<\mathrm{M}^{*}, \mathrm{P}^{*}>$ is stronger than that of $<\mathrm{M}, \mathrm{P}>$ if $\mathrm{M}$ is a proper subset of $\mathrm{M}^{*}$.

Finally, we turn to the representation of evidence, i.e. empirical data, for evidence will guide nomic truth approximation. In the nomic context empirical data at a given moment are typically asymmetric. They can be represented by a data theory $<\mathrm{R}, \mathrm{S}>$, where $\mathrm{R}$ indicates the so far realized possibilities, e.g. the realized physical possibilities, and $\mathrm{S}(\supseteq \mathrm{R})$ the (models of the) strongest law induced on the basis of R. Hence, cS indicates the induced nomic (e.g. physical) impossibilities. Of course, if $\mathrm{R}$ and $\mathrm{S}$ are correctly described and induced, respectively, then: $\mathrm{R} \subseteq \mathbf{T} \subseteq \mathrm{S}$, i.e. the data theory $<\mathrm{R}$, $\mathrm{S}>$ is true. To be sure, the assumption of correct data is far from trivial.

\subsection{The basic approach}

For the basic definitions (Kuipers 2016) we need first to introduce some crucial new terms. The truth-content at the $\mathrm{M}$-side is $\mathrm{M} \cap \mathbf{T}$, i.e. the set of possibilities about which the $\mathbf{M}$-side claim $(\mathbf{M} \subseteq \mathbf{T})$ is true, and the falsity-content is $\mathbf{M}-\mathbf{T}$, i.e. the set of

$\overline{7 \text { In special cases, } V \text { may not be rich enough to precisely characterize }} \mathbf{T}$ in some finite way. 
possibilities about which the M-side claim is false. Similarly, the truth-content at the $\mathrm{P}$-side is $\mathrm{cP} \cap \mathrm{cT}$ and the falsity-content is $\mathrm{cP}-\mathrm{cT}$. Note that in both cases, their union $\mathrm{M}$ and $\mathrm{cP}$, respectively, may well be called the content of the theory at the relevant side.

Now the following definition is plausible.

Definition 1:

Theory $<\mathrm{M}^{*}, \mathrm{P}^{*}>$ is basically at least as close to the truth $<\mathbf{T}, \mathbf{T}>$ as $<\mathrm{M}, \mathrm{P}>$ iff:

TC-clauses

The truth-content on both sides of $<\mathrm{M}, \mathrm{P}>$ is a subset of the truth-content at the corresponding side of $\left\langle\mathrm{M}^{*}, \mathrm{P}^{*}>: \mathrm{M} \cap \mathbf{T} \subseteq \mathrm{M}^{*} \cap \mathbf{T}\left(\equiv \mathbf{T}-\mathrm{M}^{*} \subseteq \mathbf{T}-\mathbf{M}\right)\right.$ and $\mathrm{PP} \cap \mathrm{c} \mathbf{T}$ $\subseteq \mathrm{cP} * \cap \mathrm{cT}\left(\equiv \mathrm{P}^{*}-\mathbf{T} \subseteq \mathrm{P}-\mathbf{T}\right)$.

$F C$-clauses

The falsity-content on both sides of $<\mathrm{M}^{*}, \mathrm{P}^{*}>$ is a subset of the falsity-content at the corresponding side of $<\mathrm{M}, \mathrm{P}>\mathrm{:} \mathrm{M}^{*}-\mathbf{T} \subseteq \mathrm{M}-\mathbf{T}$ and $\mathrm{cP}^{*}-\mathrm{cT} \subseteq \mathrm{cP}-\mathrm{cT}$ ( $\equiv \mathbf{T}$ $\left.-\mathrm{P}^{*} \subseteq \mathbf{T}-\mathrm{P}\right)$.

It is not difficult to check that on both sides the combined clauses can be summarized in terms of symmetric differences: $\mathrm{M}^{*} \Delta \mathbf{T} \subseteq \mathrm{M} \Delta \mathbf{T}$ and $\mathrm{cP}^{*} \Delta \mathrm{cT} \subseteq \mathrm{cP} \Delta \mathrm{cT}\left(\equiv \mathrm{P}^{*}\right.$ $\Delta \mathbf{T} \subseteq \mathrm{P} \Delta \mathbf{T})$.

Of course, $<\mathrm{M}^{*}, \mathrm{P}^{*}>$ is said to be basically closer to the truth $<\mathbf{T}, \mathbf{T}>$ than $<\mathrm{M}, \mathrm{P}>$ if at least one of the subset relations is proper.

Now we turn to some notions that take evidence $<\mathrm{R}, \mathrm{S}>$ into account, where we assume to have accepted its claims: $\mathrm{R} \subseteq \mathbf{T}$ and $\mathbf{T} \subseteq \mathrm{S}(\equiv \mathrm{cS} \subseteq \mathrm{cT})$. The acceptedcontent at the $\mathrm{M}$-side is $\mathrm{M} \cap \mathrm{R}$, i.e. the set of possibilities about which the $\mathrm{M}$-side claim $(\mathrm{M} \subseteq \mathbf{T})$ has been accepted, and the rejected-content is $\mathrm{M}-\mathrm{S}$, i.e. the set of possibilities about which the M-side claim has been rejected, which is easy to check. Similarly, the accepted-content at the $\mathrm{P}$-side is $\mathrm{cP} \cap \mathrm{cS}$ and the rejected-content is $\mathrm{cP}-\mathrm{cR}(\equiv \mathrm{R}-\mathrm{P})$.

Now the following definition is also plausible.

Definition 2:

Theory $<\mathrm{M}^{*}, \mathrm{P}^{*}>$ is, relative to $<\mathrm{R}, \mathrm{S}>$, basically at least as successful as $<\mathrm{M}, \mathrm{P}>$ iff: AC-clauses

The accepted-content on both sides of $<\mathrm{M}, \mathrm{P}>$ is a subset of the accepted-content at the corresponding side of $<\mathrm{M}^{*}, \mathrm{P}^{*}>: \mathrm{M} \cap \mathrm{R} \subseteq \mathrm{M}^{*} \cap \mathrm{R}\left(\equiv \mathrm{R}-\mathrm{M}^{*} \subseteq \mathrm{R}-\mathrm{M}\right)$ and $\mathrm{cP} \cap \mathrm{cS} \subseteq \mathrm{cP}^{*} \cap \mathrm{cS}\left(\equiv \mathrm{P}^{*}-\mathrm{S} \subseteq \mathrm{P}-\mathrm{S}\right)$.

$R C$-clauses

The rejected-content on both sides of $<\mathrm{M}^{*}, \mathrm{P}^{*}>$ is a subset of the rejected-content at the corresponding side of $<\mathrm{M}, \mathrm{P}>: \mathrm{M}^{*}-\mathrm{S} \subseteq \mathrm{M}-\mathrm{S}$ and $\mathrm{cP}^{*}-\mathrm{cR} \subseteq \mathrm{cP}-\mathrm{cR}$ $\left(\equiv \mathrm{R}-\mathrm{P}^{*} \subseteq \mathrm{R}-\mathrm{P}\right)$.

Of course, $<\mathrm{M}^{*}, \mathrm{P}^{*}>$ is said to be basically more successful relative to $<\mathrm{R}, \mathrm{S}>$ than $<\mathrm{M}, \mathrm{P}>$ if at least one of the subset relations is proper.

We close with a not surprising but crucial theorem.

Theorem 1 Basic Success Theorem

If $<\mathrm{M}^{*}, \mathrm{P}^{*}>$ is basically at least as close to the truth $<\mathrm{T}, \mathrm{T}>$ as $<\mathrm{M}, \mathrm{P}>$ then, assuming correct data $<\mathrm{R}, \mathrm{S}>$, i.e. $\mathrm{R} \subseteq \mathbf{T} \subseteq \mathrm{S},<\mathrm{M}^{*}, \mathrm{P}^{*}>$ is, relative to $<\mathrm{R}, \mathrm{S}>$, basically at least as successful as $<\mathrm{M}, \mathrm{P}>$. 
The proof is straightforward. The remaining methodological steps to complete the basic theory of nomic truth approximation are analogous to those of the refined theory, for which we refer to the end of Sect. 3 .

\section{The refined approach}

In (Kuipers 2000, Chapter 10) I have introduced refined nomic truth approximation for maximal theories in order to compensate for the following problem of basic truth approximation: any mistake is as worse as any other. For that purpose I introduced the ternary similarity relation $s(x, y, z)$ between structures in $U: \mathrm{y}$ is at least as similar to $\mathrm{z}$ as $\mathrm{x} .{ }^{8}$ Structures $\mathrm{x}$ and $\mathrm{y}$ are called comparable or related, $\mathrm{r}(\mathrm{x}, \mathrm{z})$, iff there is a $y$ such that $\mathrm{s}(\mathrm{x}, \mathrm{y}, \mathrm{z})$. The basic idea behind $\mathrm{r}(\mathrm{x}, \mathrm{z})$ is not the existence of a proper intermediate, i.e. a $\mathrm{y}$ different from $\mathrm{x}$ and $\mathrm{z}$, but only that $\mathrm{x}$ and $\mathrm{z}$ have at least so much in common that it makes sense to talk about (proper and improper) intermediates.

The relation $\mathrm{s}$ is supposed to satisfy the following 'minimal' s-conditions: centered, centering and conditionally left and right reflexive. For all $\mathrm{x}, \mathrm{y}, \mathrm{z}, \mathrm{s}$ is centered iff $\mathrm{s}(\mathrm{x}$, $\mathrm{x}, \mathrm{x})$ and centering iff $\mathrm{s}(\mathrm{x}, \mathrm{y}, \mathrm{x})$ implies $\mathrm{x}=\mathrm{y}$. Moreover, $\mathrm{s}$ is conditionally left/right reflexive if $\mathrm{s}(\mathrm{x}, \mathrm{y}, \mathrm{z})$ implies all kinds of left and right reflexivity, i.e., $\mathrm{s}(\mathrm{x}, \mathrm{x}, \mathrm{y}), \mathrm{s}(\mathrm{x}, \mathrm{x}$, $\mathrm{z}), \mathrm{s}(\mathrm{y}, \mathrm{y}, \mathrm{z})$ and $\mathrm{s}(\mathrm{x}, \mathrm{y}, \mathrm{y}), \mathrm{s}(\mathrm{x}, \mathrm{z}, \mathrm{z}), \mathrm{s}(\mathrm{y}, \mathrm{z}, \mathrm{z})$, respectively. Note that the conditional form, by assuming $\mathrm{s}(\mathrm{x}, \mathrm{y}, \mathrm{z})$, leaves room for incomparable structures; without this assumption, $\mathrm{s}(\mathrm{x}, \mathrm{x}, \mathrm{y})$ for example would entail $\mathrm{r}(\mathrm{x}, \mathrm{y})$, for all $\mathrm{x}$ and $\mathrm{y}$. The relation $\mathrm{s}$ is trivial if $\mathrm{s}(\mathrm{x}, \mathrm{y}, \mathrm{z})$ iff $\mathrm{x}=\mathrm{y}=\mathrm{z}$.

A plausible example of such a s-relation we get in the case the conceptual possibilities consist of the propositional constituents generated by a finite number $\mathrm{n}$ of elementary propositions $\mathrm{p}_{1}, \mathrm{p}_{2}, \ldots \mathrm{p}_{\mathrm{n}}:( \pm) \mathrm{p}_{1} \&( \pm) \mathrm{p}_{2} \& \ldots( \pm) \mathrm{p}_{\mathrm{n}}$, where each $( \pm)$ is either a negation sign or no sign at all. It is plausible to say that e.g. $\neg \mathrm{p}_{1} \& \mathrm{p}_{2}$ is more similar to $\mathrm{p}_{1} \& \mathrm{p}_{2}$ than $\neg \mathrm{p}_{1} \& \neg \mathrm{p}_{2}$. In general, for propositional constituents $\mathrm{x}, \mathrm{y}, \mathrm{z}, \mathrm{y}$ is more similar to $\mathrm{z}$ than $\mathrm{x}$ when $\mathrm{y}$ agrees with more (non-)negation signs of $\mathrm{z}$ than $\mathrm{x}$. This qualitative definition, called the basic s-relation, transforms into a quantitative version by just comparing the number of agreements. ${ }^{9}$ We get an interpretation of the r-relation by enlarging $U$ to all (partial) constituents generated by a selection of elementary propositions out of a given set: $\mathrm{r}(\mathrm{x}, \mathrm{y})$ then amounts to ' $\mathrm{x}$ and $\mathrm{y}$ are generated by the same selection'. Hence, $\mathrm{p}_{1} \& \mathrm{p}_{2}$ and $\neg \mathrm{p}_{1} \& \mathrm{p}_{2}$ are comparable, but $\mathrm{p}_{1} \& \mathrm{p}_{2}$ and $\neg \mathrm{p}_{1}$ are not.

To take account of structurelikeness, we start with introducing some new general terminology, again suitable for both sides. In this section, MP will be short for $<\mathrm{M}$, $\mathrm{P}>$, and hence $\mathbf{T T}=<\mathrm{T}, \mathbf{T}>$ and $\mathrm{RS}$ for $<\mathrm{R}, \mathrm{S}>$. The important new terms with respect to theory MP need all some reflection to understand the underlying idea. They are the following ones: a theory's missing content, viz. $\mathrm{M}-\mathbf{T}$ and $\mathrm{cP}-\mathrm{cT}$, respectively; its maximally possible falsity- (or false) content, viz. $\mathrm{M}-\mathrm{R}$ and $\mathrm{cP}-\mathrm{cS}$, respectively; and its maximally possible missing content, viz. $\mathrm{S}-\mathrm{M}$ and $\mathrm{cR}-\mathrm{cP}$, respectively. Table 1 summarizes all relevant previously introduced and new notions, including

\footnotetext{
8 The ternary relation may be based on Northcott (2013), who focuses on comparisons of the (causally specified, quantitative) verisimilitude of specific models.

9 This measure is known as the Clifford measure among constituents (Niiniluoto 1987, p. 311).
} 
Table 1 Crucial notions

\begin{tabular}{|c|c|c|c|}
\hline Theory $\mathrm{MP}=<\mathrm{M}, \mathrm{P}\rangle$ & $\mathrm{k} \in\{\mathrm{m}, \mathrm{p}\}$ & $\mathrm{m}=\mathrm{M}$-side & $\mathrm{p}=\mathrm{P}$-side \\
\hline Claim of MP & $\mathrm{Cl}_{\mathrm{k}}(\mathrm{MP})$ & $\mathrm{M} \subseteq \mathbf{T}$ & $\begin{array}{l}\mathbf{T} \subseteq \mathrm{P} \\
(\mathrm{cP} \subseteq \mathrm{cT})\end{array}$ \\
\hline Content of MP & $\mathrm{C}_{\mathrm{k}}(\mathrm{MP})$ & M & $\mathrm{cP}$ \\
\hline Content of $\mathbf{T T}=\langle\mathbf{T}, \mathbf{T}\rangle$ & $\mathrm{C}_{\mathrm{k}}(\mathbf{T T})$ & $\mathbf{T}$ & $\mathrm{cT}$ \\
\hline Truth-content of MP & $\mathrm{TC}_{\mathrm{k}}(\mathrm{MP})$ & $\mathrm{M} \cap \mathbf{T}$ & $\mathrm{cP} \cap \mathrm{c} \mathbf{T}$ \\
\hline $\begin{array}{l}\text { Falsity- (or false) } \\
\text { content of MP }\end{array}$ & $\mathrm{FC}_{\mathrm{k}}(\mathrm{MP})$ & $\mathbf{M}-\mathbf{T}$ & $\begin{array}{l}\mathrm{cP}-\mathrm{c} \mathbf{T} \\
(\mathbf{T}-\mathrm{P})\end{array}$ \\
\hline Missing content of MP & $\mathrm{MC}_{\mathrm{k}}(\mathrm{MP})$ & $\mathbf{T}-\mathbf{M}$ & $\mathrm{c} \mathbf{T}-\mathrm{cP}$ \\
\hline $\begin{array}{l}\text { Claim of data theory } \\
\mathrm{RS}=<\mathrm{R}, \mathrm{S}>\text {, assumed } \\
\text { to be accepted! }\end{array}$ & $\mathrm{Cl}_{\mathrm{k}}(\mathrm{RS})$ & $\mathrm{R} \subseteq \mathbf{T}$ & $\begin{array}{l}\mathbf{T} \subseteq \mathrm{S} \\
(\mathrm{cS} \subseteq \mathrm{cT})\end{array}$ \\
\hline Content of RS & $\mathrm{C}_{\mathrm{k}}(\mathrm{RS})$ & $\mathrm{R}$ & $\mathrm{cS}$ \\
\hline Accepted-content of MP & $\mathrm{AC}_{\mathrm{k}}(\mathrm{MP})$ & $\mathrm{M} \cap \mathrm{R}$ & $\mathrm{cP} \cap \mathrm{cS}$ \\
\hline Rejected-content of MP & $\mathrm{RC}_{\mathrm{k}}(\mathrm{MP})$ & $M-S$ & $\mathrm{cP}-\mathrm{cR}$ \\
\hline $\begin{array}{l}\text { Maximally possible } \\
\text { falsity-(or false) } \\
\text { content of MP }\end{array}$ & $\mathrm{MPFC}_{\mathrm{k}}(\mathrm{MP})$ & $M-R$ & $\mathrm{cP}-\mathrm{cS}$ \\
\hline $\begin{array}{l}\text { Maximally possible } \\
\text { missing content of MP }\end{array}$ & $\mathrm{MPMC}_{\mathrm{k}}(\mathrm{MP})$ & $\mathrm{S}-\mathrm{M}$ & $\mathrm{cR}-\mathrm{cP}$ \\
\hline
\end{tabular}

side-independent symbols for them. The sides are indicated by $\mathrm{m}$ and $\mathrm{p}$, respectively, with variable $\mathrm{k}$.

The new notions enable conceptually plausible refined definitions of 'at least as close to the truth' and 'at least as successful'. The idea behind 'MP* is refined at least as close to the truth as MP' is that MP* includes and excludes items at least as adequately as MP. More precisely, first, MP* at least matches up to MP in representing TT in the following sense: for each individual claim of MP and each related individual claim of TT MP* has an individual claim that is at least as good in representing that claim of TT as that of MP does, and, second, all extra, but mistaken, claims of MP* are useful in matching up to MP in the indicated way. In still other words, $<\mathrm{M}^{*}$, $\mathrm{P}^{*}>$ characterizes, by $\mathrm{M}^{*}$ and $\mathrm{cP}^{*}$, respectively, what is to be included and excluded, i.e. $\mathbf{T}$ and $\mathrm{cT}$, at least as precisely as $<\mathrm{M}, \mathrm{P}>$ does by $\mathrm{M}$ and $\mathrm{cP}$.

For all clauses in the following definition there will first be given a general verbal formulation, followed by a general formalization, and finally a side-wise decomposition.

Definition 3:

$\mathrm{MP}^{*}=<\mathrm{M}^{*}, \mathrm{P}^{*}>$ is refined at least as close to the truth $\mathbf{T T}=<\mathbf{T}, \mathbf{T}>$ as $\mathrm{MP}=<\mathrm{M}$, $\mathrm{P}>$ iff

(i) Likeness-clauses (or refined TC-clauses)

For either side $\mathrm{k}$ in $\{\mathrm{m}, \mathrm{p}\}$, for all $\mathrm{x}$ in the k-content of MP and for all $\mathrm{z}$ in the $\mathrm{k}$-content of TT if $\mathrm{x}$ and $\mathrm{z}$ are comparable then there is $\mathrm{y}$ in the $\mathrm{k}$-content of MP* such that $\mathrm{y}$ is between $\mathrm{x}$ and $\mathrm{z}$, i.e. 
(i) $\forall_{\mathrm{k} \in\{\mathrm{m}, \mathrm{p}\}} \forall_{\mathrm{x} \in \mathrm{Ck}(\mathrm{MP})} \forall_{\mathrm{z} \in \mathrm{Ck}(\mathrm{TT})} \mathrm{r}(\mathrm{x}, \mathrm{z}) \rightarrow \exists_{\mathrm{y} \in \mathrm{Ck}\left(\mathrm{MP}^{*}\right)} \mathrm{s}(\mathrm{x}, \mathrm{y}, \mathrm{z})$

$$
\begin{aligned}
& \dot{M}_{(i)} \forall_{x \in M} \forall_{z \in T} r(x, z) \rightarrow \exists_{y \in M^{*}} s(x, y, z) \\
& \&
\end{aligned}
$$

$\mathrm{P}$ (i) $\forall_{\mathrm{x} \in \mathrm{cP}} \forall_{\mathrm{z} \in \mathrm{cT}} \mathrm{r}(\mathrm{x}, \mathrm{z}) \rightarrow \exists_{\mathrm{y} \in \mathrm{cP}} \mathrm{s}(\mathrm{x}, \mathrm{y}, \mathrm{z})$

(ii) Usefulness-clauses (or refined FC-clauses)

For either side $\mathrm{k}$ in $\{\mathrm{m}, \mathrm{p}\}$, for all $\mathrm{y}$ in the extra false k-content of $\mathrm{MP}^{*}$ (relative to MP) there are $\mathrm{x}$ in the false $\mathrm{k}$-content of MP and $\mathrm{z}$ in the missing $\mathrm{k}$-content of MP such that $\mathrm{y}$ is between $\mathrm{x}$ and $\mathrm{z}$, i.e.

(ii) $\forall_{\mathrm{k} \in\{\mathrm{m}, \mathrm{p}\}} \forall_{\mathrm{y} \in \mathrm{FCk}\left(\mathrm{MP}^{*}\right)-\mathrm{FCk}(\mathrm{MP})} \exists_{\mathrm{x} \in \mathrm{Ck}(\mathrm{MP})} \exists_{\mathrm{z} \in \mathrm{MCk}(\mathrm{MP})} \mathrm{s}(\mathrm{x}, \mathrm{y}, \mathrm{z})$

$\Leftrightarrow$

$$
\begin{aligned}
& M_{(\text {ii) }} \forall_{y \in M^{*}-(M \cup T)} \exists_{x \in M-T} \exists_{z \in T-M} s(x, y, z) \\
& \& \\
& P_{(\text {ii) })} \forall_{y \in c P^{*}-(c P \cup c T)} \exists_{x \in c P-c T} \exists_{z \in c T-c P} s(x, y, z)
\end{aligned}
$$

It is easy to check, using the minimal s-conditions, that the Likeness-clauses are stronger than the basic TC-clauses and that they reduce to these clauses when $\mathrm{s}$ is trivial: $\mathrm{s}(\mathrm{x}, \mathrm{y}, \mathrm{z})$ iff $\mathrm{x}=\mathrm{y}=\mathrm{z}$. Strictly speaking, we prefer to call the refined TC-clauses Likeness-clauses, for the term TC-clause is problematic in the refined case, for the clauses deal not only with, for example, at the $\mathrm{M}$-side $\mathrm{M} \cap \mathbf{T}$ and $\mathbf{M}^{*} \cap \mathbf{T}$, in the same way as the basic clauses, but also with $\mathbf{M}-\mathbf{T}$ and $\mathbf{M}^{*}$ in general. In the next section we will give a table with their decomposition, showing in detail that and how they are stronger than the basic clauses.

Note that, in contrast, the refined FC-clauses, which we also call Usefulness-clauses, are weaker than the basic FC-clauses and reduce to these clauses when $\mathrm{s}$ is trivial. However, they are not only trivially entailed by them, since $\mathrm{M}^{*}-(\mathrm{M} \cup \mathbf{T})$ and $\mathrm{cP}^{*}-(\mathrm{cP} \cup \mathrm{cT})$ become empty, but they remain to deal only with the (extra) falsity-content (of MP* relative to MP). Hence, they can rightly be called refined FC-clauses. For this reason, we will continue to also speak of the refined TC- and FC-clauses, despite the somewhat misleading term 'refined TCclause'.

Turning to the definition of 'MP is refined at least as successful as MP*' the idea is that MP* includes and excludes accepted items at least as adequate as MP.

\section{Definition 4:}

$\mathrm{MP}^{*}=<\mathrm{M}^{*}, \mathrm{P}^{*}>$ is, relative to $\mathrm{RS}=<\mathrm{R}, \mathrm{S}>$, refined at least as successful as

$\mathrm{MP}=<\mathrm{M}, \mathrm{P}>$ iff

(i) ${ }^{\mathrm{RS}}$ Accepted Likeness-clause (refined AC-clause)

For either side $\mathrm{k}$ in $\{\mathrm{m}, \mathrm{p}\}$, for all $\mathrm{x}$ in the $\mathrm{k}$-content of $\mathrm{MP}$ and for all $\mathrm{z}$ in the $\mathrm{k}$-content of RS if $\mathrm{x}$ and $\mathrm{z}$ are comparable then there is $\mathrm{y}$ in the k-content of MP* such that $y$ is between $x$ and $z$, i.e.

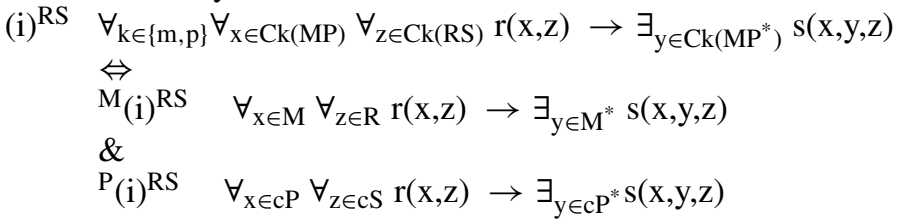


(ii) ${ }^{\mathrm{RS}}$ Accepted Usefulness-clause (refined RC-clause)

For either side $\mathrm{k}$ in $\{\mathrm{m}, \mathrm{p}\}$, for all $\mathrm{y}$ in the extra rejected k-content of MP* (relative to MP) there are $\mathrm{x}$ in the maximally possible false k-content of MP and $\mathrm{z}$ in the maximally possible missing $\mathrm{k}$-content of MP such that $\mathrm{y}$ is between $x$ and $z$, i.e.

$$
\begin{aligned}
& \text { (ii) }^{\mathrm{RS}} \quad \forall_{\mathrm{k} \in\{\mathrm{m}, \mathrm{p}\}} \forall_{\mathrm{y} \in \mathrm{RCk}\left(\mathrm{MP}^{*}\right)-\mathrm{RCk}(\mathrm{MP})} \exists_{\mathrm{x} \in \operatorname{MPFCk}(\mathrm{MP})} \exists_{\mathrm{z} \in \operatorname{MPMCk}(\mathrm{MP})} \mathrm{s}(\mathrm{x}, \mathrm{y}, \mathrm{z}) \\
& \Leftrightarrow \mathrm{M}_{(\mathrm{ii})} \mathrm{RS} \quad \forall_{\mathrm{y} \in \mathrm{M}^{*}-(\mathrm{M} \cup \mathrm{S})} \exists_{\mathrm{x} \in \mathrm{M}-\mathrm{R}} \exists_{\mathrm{z} \in \mathrm{S}-\mathrm{M}} \mathrm{s}(\mathrm{x}, \mathrm{y}, \mathrm{z}) \\
&\stackrel{\mathrm{P}}{(\mathrm{ii})})^{\mathrm{RS}} \forall_{\mathrm{y} \in \mathrm{cP} \mathrm{P}^{*}-(\mathrm{cP} \cup \mathrm{cR})} \exists_{\mathrm{x} \in \mathrm{cP}-\mathrm{cS}} \exists_{\mathrm{z} \in \mathrm{cR}-\mathrm{cP}} \mathrm{s}(\mathrm{x}, \mathrm{y}, \mathrm{z})
\end{aligned}
$$

Now we can summarize clause (i) ${ }^{\mathrm{RS}}$ by: MP* at least matches up to MP in representing $\mathrm{RS}$, and clause (ii) ${ }^{\mathrm{RS}}$ by: all extra, but mistaken, items of MP* are useful in matching up to MP in representing $\mathrm{RS}$.

Again, it is easy to check, using the minimal s-conditions, that the Accepted Likeness-clauses are stronger than the basic AC-clauses, enabling again a plausible decomposition, and that they reduce to these clauses when s is trivial. Similarly, it is easy to check that the Accepted Usefulness-clauses are weaker than the basic RCclauses and that they reduce to these clauses when s is trivial. Terminologically, similar remarks apply: a preference to speak of Accepted Likeness-clauses instead of refined AC-clauses, but no preference between speaking of Accepted Usefulness-clauses and refined RC-clauses.

As announced, the new, more conceptual, approach suggested the above presented revised definition of 'refined at least as successful', such that we can now (easily) prove that the two notions are ideally related, the first entails the second unconditionally.

Theorem 2 Refined Success Theorem

If $\mathrm{MP}^{*}=<\mathrm{M}^{*}, \mathrm{P}^{*}>$ is refined at least as close to $\mathbf{T T}$ as $\mathrm{MP}=<\mathrm{M}, \mathrm{P}>$ and assuming correct data $\mathrm{RS}=<\mathrm{R}, \mathrm{S}>$ then $\mathrm{MP}^{*}$ is, relative to RS, refined at least as successful as MP*.

Let us conclude this section by formulating the remaining methodological steps to complete the refined theory of nomic truth approximation ${ }^{10}$ : assuming that a new theory is at a certain moment refined more successful than the old one, propose and test the 'refined empirical progress hypothesis': the new theory (is and) remains refined more successful than the old one. Assuming that after 'sufficient confirmation' this 'refined empirical progress hypothesis' is accepted (for the time being), argue on the basis of a reconstruction of the way in which experiments have been done and the Refined Success Theorem, that the 'default explanation' for this case of refined empirical progress is the hypothesis that the new theory is refined closer to the truth than the old one, i.e. that this is a case of refined truth approximation. Finally, conclude abductively (for the time being) that the new theory is refined closer to the truth than the old one, i.e. that refined truth approximation has been achieved.

It should be noted that, different from the basic and even more from the quantitative case, the comparative relations of 'closer to' and 'more successful' in the refined

10 The main lines are the same as those for the basic account. 
sense presuppose very special conditions and hence will seldom hold in full strength. However, in the context of 'idealization and concretization' such relations may well hold as we will argue in Sect. $5 .{ }^{11}$ But first we will summarize the above in a number of tables.

\section{A summary in tables}

In this section, the main points of the previous section will be summarized in some handsome tables, leaving out the side-independent conceptually motivated formulations, and hence we can return to the $<\mathrm{M}, \mathrm{P}>$ - and $<\mathrm{R}, \mathrm{S}>$-representation of theories and evidence. Table 2 summarizes the claims that $\left\langle\mathrm{M}^{*}, \mathrm{P}^{*}\right\rangle$ is basically and refined at least as close to the truth as $<\mathrm{M}, \mathrm{P}>$.

Again, as in the basic and quantitative cases, it is interesting to combine, in Table 3, the refined TC- and FC-clauses, in particular for maximal theories.

Table 4 summarizes the claims that $<\mathrm{M}^{*}, \mathrm{P}^{*}>$ is basically and refined at least as successful as $<\mathrm{M}, \mathrm{P}>$, relative to $<\mathrm{R}, \mathrm{S}>$.

Finally, Table 5 shows how the (Accepted) Likeness-clauses can be decomposed in the corresponding basic clauses and extra clauses dealing with the (maximally possible) falsity-content.

\section{Idealization and concretization}

In this section ${ }^{12}$ it will be pointed out that 'idealization and concretization' is a special kind of (potential) refined truth approximation. This is illustrated by Van der Waals's theory of gases. Moreover, it is indicated how idealization and concretization can function as a strategy in validity research around 'interesting theorems'. The present section is restricted to inclusion theories ('pure theories of models'), that is, theories that only specify classes of models, hence theories of the form $\langle\mathrm{M}, \emptyset\rangle$, which notation will be reduced to $M$.

\subsection{Truth approximation by (idealization and) concretization}

Concretization or factualization, as it has been presented by the Polish philosophers Władysław Krajewski (1977) and Leszek Nowak (1980), is basically a relation between real-valued functions. Hence, let us assume that the conceptual possibilities (structures) to be considered contain one or more real-valued functions, with or without one or more real constants. Structure $\mathrm{y}$ is called a concretization of $\mathrm{x}$ and $\mathrm{x}$ an idealization of $\mathrm{y}$, indicated by $\operatorname{con}(\mathrm{x}, \mathrm{y})$, if $\mathrm{y}$ transforms, directly or by a limit procedure, into $\mathrm{x}$ when one or more constants occurring in $\mathrm{y}$ assume the value 0 . It is

\footnotetext{
11 A formal way to increase the applicability of the refined approach is by setting up a quantitative refined version by introducing a distance function between the conceptual possibilities. In Kuipers (2000, Chap. 12) this has been done assuming maximal theories. We leave it as a challenge to do so for two-sided theories.

12 This section is heavily based on Section 10.4 of (Kuipers 2000).
} 


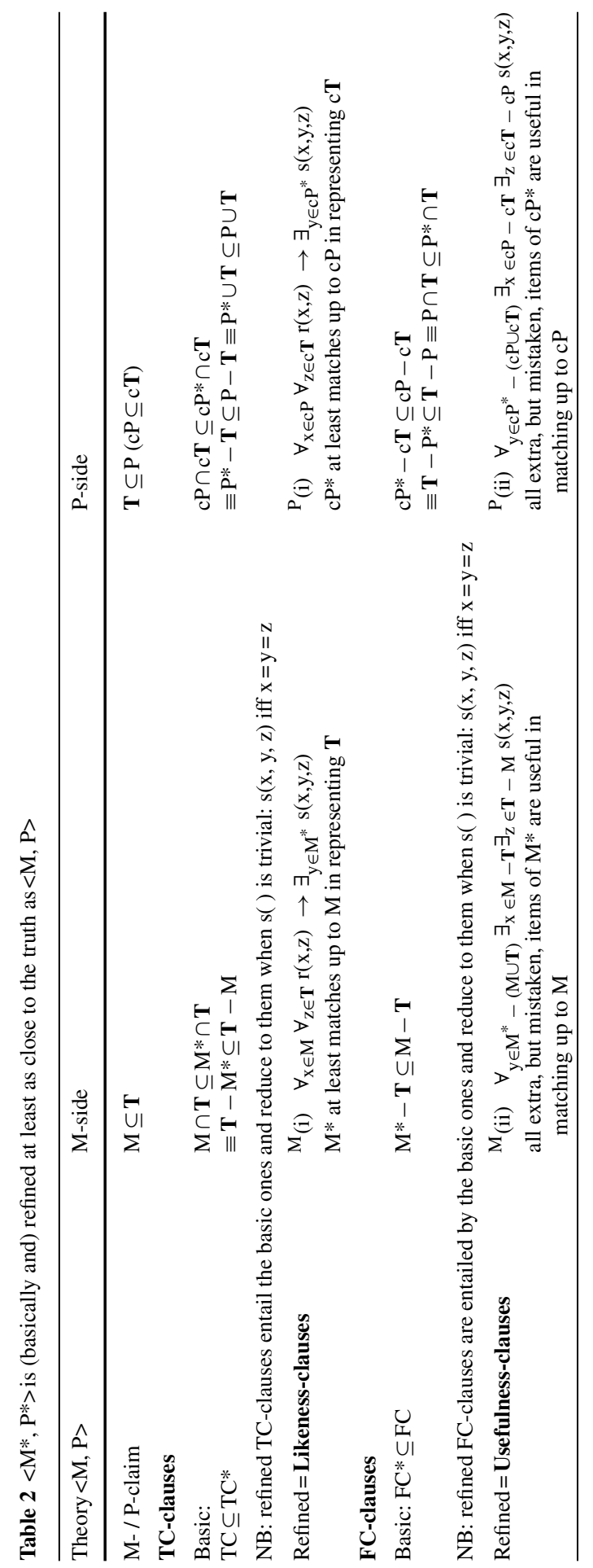




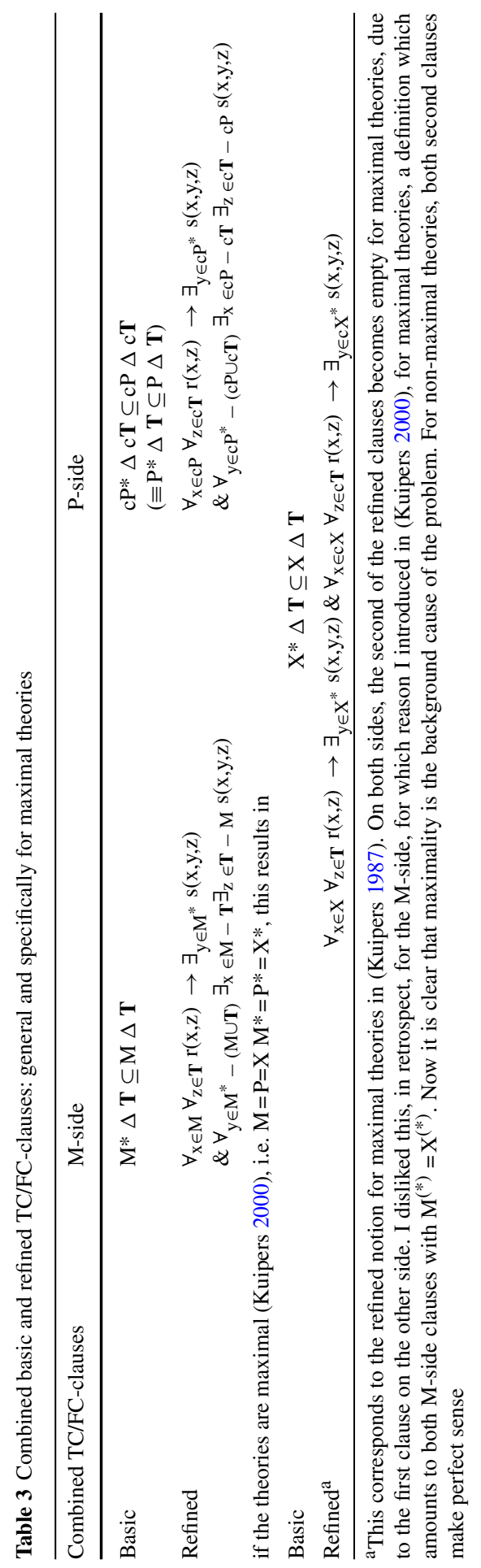




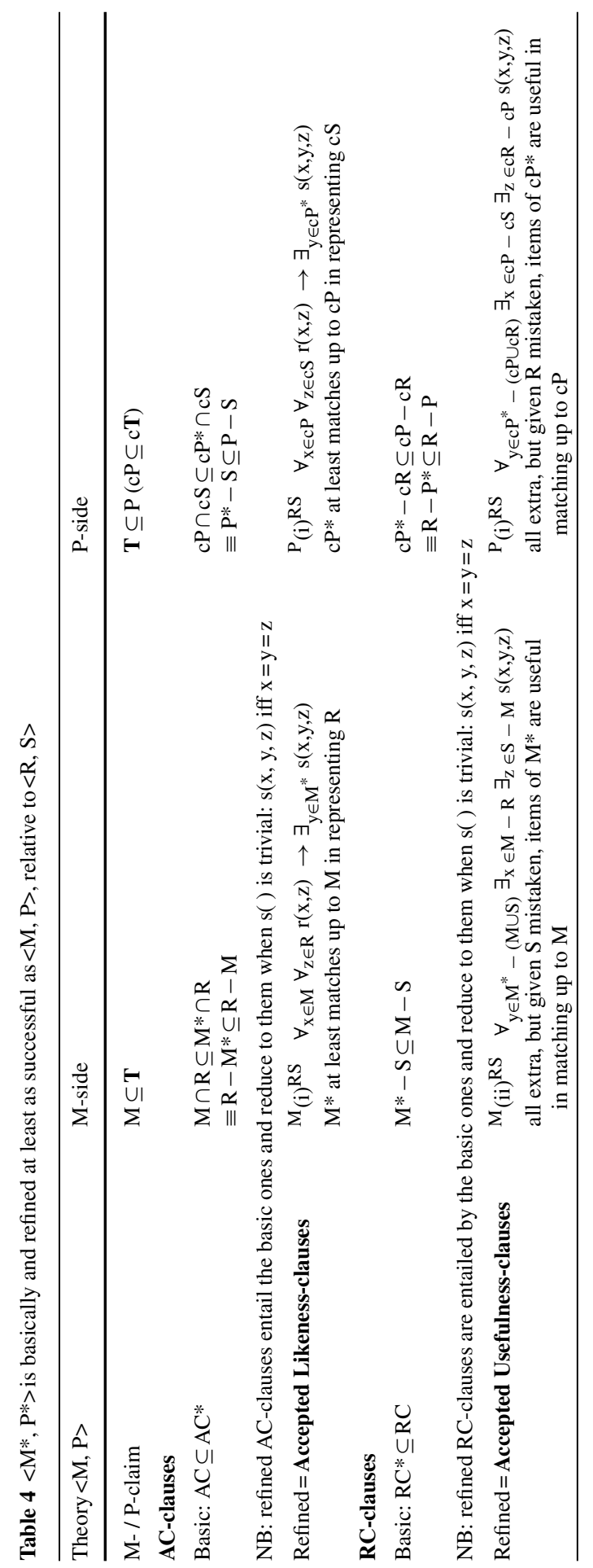


Table 5 Decomposition of the (accepted) likeness-clauses

\begin{tabular}{|c|c|c|}
\hline $\begin{array}{l}\text { Likeness-clauses: } \\
\text { decomposition in basic } \\
\text { TC-clause \& extra clause }\end{array}$ & $\begin{array}{l}\forall_{\mathrm{x} \in \mathrm{M}} \forall_{\mathrm{z} \in \mathbf{T}} \mathrm{r}(\mathrm{x}, \mathrm{z}) \rightarrow \\
\quad \exists_{\mathrm{y} \in \mathrm{M}^{*} \mathrm{~s}(\mathrm{x}, \mathrm{y}, \mathrm{z})} \\
\equiv \\
\mathrm{M} \cap \mathbf{T} \subseteq \mathrm{M}^{*} \cap \mathbf{T} \\
\& \\
\forall_{\mathrm{x} \in \mathrm{M}-\mathbf{T}} \forall_{\mathrm{z} \in \mathbf{T}} \mathrm{r}(\mathrm{x}, \mathrm{z}) \rightarrow \\
\quad \exists_{\mathrm{y} \in \mathrm{M}^{*} \mathrm{~s}(\mathrm{x}, \mathrm{y}, \mathrm{z})}\end{array}$ & $\begin{array}{l}\forall_{\mathrm{x} \in \mathrm{cP}} \forall_{\mathrm{z} \in \mathrm{cT}} \mathrm{r}(\mathrm{x}, \mathrm{z}) \rightarrow \\
\quad \exists_{\mathrm{y} \in \mathrm{cP}} \mathrm{s}(\mathrm{x}, \mathrm{y}, \mathrm{z}) \\
\equiv \\
\mathrm{cP} \cap \mathrm{cT} \subseteq \mathrm{cP} * \mathrm{cT} \\
\& \\
\forall_{\mathrm{x} \in \mathrm{cP}-\mathrm{cT}} \forall_{\mathrm{z} \in \mathrm{c} \mathbf{T}} \mathrm{r}(\mathrm{x}, \mathrm{z}) \rightarrow \\
\quad \exists_{\mathrm{y} \in \mathrm{cP}} \mathrm{s}(\mathrm{x}, \mathrm{y}, \mathrm{z})\end{array}$ \\
\hline $\begin{array}{l}\text { Accepted Likeness-clauses: } \\
\text { decomposition in basic } \\
\text { AC-clause \& extra clause }\end{array}$ & $\begin{array}{l}\forall_{\mathrm{x} \in \mathrm{M}} \forall_{\mathrm{z} \in \mathrm{R}} \mathrm{r}(\mathrm{x}, \mathrm{z}) \rightarrow \\
\quad \exists_{\mathrm{y} \in \mathrm{M}^{*} \mathrm{~s}(\mathrm{x}, \mathrm{y}, \mathrm{z})} \\
\equiv \\
\mathrm{M} \cap \mathrm{R} \subseteq \mathrm{M}^{*} \cap \mathrm{R} \\
\& \\
\forall_{\mathrm{x} \in \mathrm{MR}} \forall_{\mathrm{z} \in \mathrm{R}} \mathrm{r}(\mathrm{x}, \mathrm{z}) \rightarrow \\
\quad \exists_{\mathrm{y} \in \mathrm{M}^{*} \mathrm{~s}(\mathrm{x}, \mathrm{y}, \mathrm{z})}\end{array}$ & $\begin{array}{l}\forall_{\mathrm{x} \in \mathrm{cP}} \forall_{\mathrm{z} \in \mathrm{cS}} \mathrm{r}(\mathrm{x}, \mathrm{z}) \rightarrow \\
\quad \exists_{\mathrm{y} \in \mathrm{cP}} * \mathrm{~s}(\mathrm{x}, \mathrm{y}, \mathrm{z}) \\
\equiv \\
\mathrm{cP} \cap \mathrm{cS} \subseteq \mathrm{cP} * \cap \mathrm{cS} \\
\& \\
\forall_{\mathrm{x} \in \mathrm{cPcS}} \forall_{\mathrm{z} \in \mathrm{cS}} \mathrm{r}(\mathrm{x}, \mathrm{z}) \rightarrow \\
\quad \exists_{\mathrm{y} \in \mathrm{cP}} * \mathrm{~s}(\mathrm{x}, \mathrm{y}, \mathrm{z})\end{array}$ \\
\hline
\end{tabular}

easy to see that it is a necessary condition for con ( $\mathrm{x}, \mathrm{y})$ that $\mathrm{x}$ and $\mathrm{y}$ have the same domain-sets. Moreover, it is easy to check that con is reflexive, antisymmetric and transitive. In a subsection to follow, the example of a Van der Waals gas model will be presented as a concretization of an ideal gas model.

Concretization is primarily a binary relation, but for our purposes, we need the plausible ternary version leading to a concretization triple: $\operatorname{ct}(\mathrm{x}, \mathrm{y}, \mathrm{z})$ if and only if $\operatorname{con}(\mathrm{x}, \mathrm{y})$ and $\operatorname{con}(\mathrm{y}, \mathrm{z})$. We will assume ct as the underlying notion of structurelikeness. The relation of relatedness based on ct is easily seen to be equivalent to con. Note that we have here a clear example in which relatedness is not symmetric, but directed. Note also that ct is trivially decomposable. It is easy to check that ct satisfies the minimal s-conditions of being centered, centering and conditionally left and right reflexive. Moreover, it is antisymmetric (central, left and right) and it satisfies all conceivable kinds of transitivity, e.g., left: if $\operatorname{ct}(w, x, z)$ and $\operatorname{ct}(x, y, z$,$) then \operatorname{ct}(w, y, z)$. The relation of more truth-(theory-) likeness, $\mathbf{M}^{*}$ is closer to $\mathbf{T}\left(\mathbf{M}^{* *}\right)$ than $\mathbf{M}$, based on this ternary relation, will be indicated by $\operatorname{MTLct}\left(\mathbf{M}, \mathbf{M}^{*}, \mathbf{T}\right)$ and $\operatorname{MTLct}\left(\mathbf{M}, \mathbf{M}^{*}\right.$, $\left.\mathrm{M}^{* *}\right)$, respectively.

Our next task is to define the binary relation of concretization between theories. Again we will do this as weakly as possible: $\mathrm{M}^{*}$ is a concretization of $\mathrm{M}$ and $\mathrm{M}$ an idealization of $\mathrm{M}^{*}$, indicated by $\operatorname{CON}\left(\mathrm{M}, \mathrm{M}^{*}\right)$, if and only if all members of $\mathrm{M}$ have a concretization in $\mathrm{M}^{*}$ and all members of $\mathrm{M}^{*}$ have an idealization in $\mathrm{M}$. At first sight, one might think that the second clause should be strengthened to: and all members of $\mathrm{M}^{*}$ have a unique idealization in $\mathrm{M}$. However, this would exclude e.g., 'inclusive' concretization triples $<\mathrm{M}, \mathrm{M}^{*}, \mathrm{M}^{* *}$ ) with $\mathrm{M}$ as subset of $\mathrm{M}^{*}$ and $\mathrm{M}^{*}$ of $\mathrm{M}^{* *}$ and $\mathrm{CON}\left(\mathrm{M}, \mathrm{M}^{*}\right)$ and $\mathrm{CON}\left(\mathrm{M}^{*}, \mathrm{M}^{* *}\right)$.

It is trivial that $\mathrm{CON}$ is reflexive and transitive. However, contrary to what one might expect, it need not be antisymmetric. But sufficient for antisymmetry of CON $\left(\mathrm{M}, \mathrm{M}^{*}\right)$ is that $\mathrm{M}$ and $\mathrm{M}^{*}$ are convex (i.e., closed for intermediates). Here convexity of $\mathrm{M}$ amounts to: if $\operatorname{con}(\mathrm{x}, \mathrm{y})$ and $\operatorname{con}(\mathrm{y}, \mathrm{z})$, i.e., $\operatorname{ct}(\mathrm{x}, \mathrm{y}, \mathrm{z})$, and $\mathrm{x}$ and $\mathrm{z}$ are in $\mathrm{M}$, then $\mathrm{y}$ is in $\mathrm{M}$. 
The ternary relation of concretization of theories we define again as weakly as possible: $\mathrm{CT}\left(\mathrm{M}, \mathrm{M}^{*}, \mathrm{M}^{* *}\right)$ if and only if $\operatorname{CON}\left(\mathrm{M}, \mathrm{M}^{*}\right)$ and $\operatorname{CON}\left(\mathrm{M}^{*}, \mathrm{M}^{* *}\right)$. It is easy to check that CT has the properties of being centered, centering for convex sets, and conditional left and right reflexivity, antisymmetry (central, left, right) for convex sets and all conceivable forms of transitivity. As a consequence, CT(M, $\left.\mathbf{M}^{*}, \mathbf{M}^{* *}\right)$ is for fixed $\mathbf{M}^{* *}$ a partial ordering as far as convex theories are concerned.

The main question is whether or under what conditions $\mathrm{CT}\left(\mathrm{M}, \mathrm{M}^{*}, \mathrm{M}^{* *}\right)$ implies $\operatorname{MTLct}\left(\mathrm{M}, \mathrm{M}^{*}, \mathrm{M}^{* *}\right)$. It turns out that some conditions have to be added to guarantee this implication, but there are some alternative possibilities. We are, of course, primarily interested in conditions on $\mathrm{M}$ and/or $\mathrm{M}^{*}$ or their combination, for in the crucial case we do not dispose of $\mathbf{M}^{* *}$, i.e., $\mathbf{T}$. One sufficient combination of conditions is the following: $\mathrm{M}^{*}$ should be convex as well as mediating, the latter condition being defined as: if $\mathrm{z}$ is a concretization of $\mathrm{x}$ and if $\mathrm{x}$ has a concretization in $\mathrm{M}^{*}$ and $\mathrm{z}$ an idealization in $\mathrm{M}^{*}$, then $\mathrm{M}^{*}$ also provides an intermediate for $\mathrm{x}$ and $\mathrm{z}$; or, more formally, if $\operatorname{con}(\mathrm{x}, \mathrm{z})$ and if there are $\mathrm{y}$ and $\mathrm{y}^{\prime}$ in $\mathrm{M}^{*} \operatorname{such}$ that $\operatorname{con}(\mathrm{x}, \mathrm{y})$ and $\operatorname{con}\left(y^{\prime}, z\right)$, then there is $y^{\prime \prime}$ in $M^{*} \operatorname{such}$ that con (x, y") and con(y", z), i.e., ct $(x, y$ ", $\mathrm{z})$.

Note that both conditions only concern $\mathrm{M}^{*}$. Although being mediating is a more specific property than convexity, it is not a very restrictive condition in the present context. Note also that it follows that any $\mathrm{M}$ can be an idealized starting point for successive concretization. However, the starting point $\mathrm{M}$ will usually even be closed for idealizations in the sense that if $\mathrm{x}$ in $\mathrm{M}$ and $\operatorname{con}\left(\mathrm{x}^{\prime}, \mathrm{x}\right)$, then $\mathrm{x}^{\prime}$ is in $\mathrm{M}$. It is easy to check that this trivially implies that $\mathrm{M}$ is convex and mediating.

Let us formally state the main claim: it is (easily) possible to prove the following Double Concretization (DC-)Theorem: if $\mathrm{CT}\left(\mathrm{M}, \mathrm{M}^{*}, \mathrm{M}^{* *}\right)$ and if $\mathrm{M}^{*}$ is convex and mediating, then MTLct(M, $\left.\mathrm{M}^{*}, \mathrm{M}^{* *}\right)$. In words: the intermediate theory of a concretization triple is closer to the third than the first, assuming that it is convex and mediating.

We may define stronger versions of concretization triples such as $\mathrm{CT}^{\#}\left(\mathrm{M}, \mathrm{M}^{*}\right.$, $\left.\mathrm{M}^{* *}\right)=\mathrm{CT}\left(\mathrm{M}, \mathrm{M}^{*}, \mathrm{M}^{* *}\right)$ and $\mathrm{M}^{*}$ convex and mediating or even $\mathrm{CT}^{\# \#}\left(\mathrm{M}, \mathrm{M}^{*}\right.$, $\left.\mathrm{M}^{* *}\right)=\mathrm{CT}^{\#}\left(\mathrm{M}, \mathrm{M}^{*}, \mathrm{M}^{* *}\right)$ and $\mathrm{M}$ and $\mathrm{M}^{* *}$ also convex. According to the DCTheorem, both are special kinds of more theorylikeness. Moreover, it has already been mentioned that $\mathrm{CT}\left(\mathrm{M}, \mathrm{M}^{*}, \mathrm{M}^{* *}\right)$ is antisymmetric (in the central sense) as soon as the three sets are convex; hence $\mathrm{CT}^{\# \#}$ is an antisymmetric special type of theorylikenes.

A direct consequence of the DC-Theorem is that, if theory $\mathrm{M}^{*}$ is a concretization of theory $\mathrm{M}$, if $\mathrm{M}^{*}$ is convex and mediating, and if the true set of nomic possibilities $\mathbf{T}$ is a concretization of $\mathbf{M}^{*}$, then $\mathbf{M}^{*}$ is closer to the truth than $\mathbf{M}$. This may be called the Truth Approximation by Double Concretization (TADC-)Corollary-a major goal of this section-viz., to show that and in what sense concretization may be a form of truth approximation. All conditions for truth approximation can be checked, except, of course, the crucial heuristic hypothesis that $\mathbf{T}$ is a concretization of $\mathrm{M}^{*}$.

To obtain 'good reasons' to assume that the required heuristic hypothesis that $\mathbf{T}$ is a concretization of $\mathbf{M}^{*}$ is true, it is important that the concretization has some 
type of (necessarily insufficient) justification, of a theoretical or empirical nature, suggesting that the account of the new factor is in the proper direction. In this respect, it is plausible to speak of theoretical and/or empirical concretization. The famous case of Van der Waals to be presented in the next subsection evidently is a case of theoretical concretization, followed by empirical support. The same holds true for Sommerfeld's concretization of the 'old quantum theory', presented in (Kuipers 2000, Chapter 11).

\subsection{Application to gas models}

The transition from the theory of ideal gases to Van der Waals's theory of gases has frequently been presented as a paradigmatic case of concretization. The challenge of any sophisticated theory of truthlikeness hence is to show that this transition can be a case of truth approximation.

The Law of Van der Waals takes, informally speaking, two factors into account that are neglected in the ideal gas law: the mutual attraction of the molecules and the volume of the molecules. The idea is that these two concretizations are successive steps in the direction of the truth. To specify this in some formal detail, we start by formulating the relevant models in elementary structuralist terms. $(\mathrm{S}, \mathrm{n}, \mathrm{P}, \mathrm{V}, \mathrm{T})$ is a potential gas model (PGM) if and only if $\mathrm{S}$ represents a set of thermal states of $n$ moles of a gas and $\mathrm{P}, \mathrm{V}$ and $\mathrm{T}$ are real-valued functions defined on $\mathrm{S}$ and representing pressure, volume and (empirical absolute) temperature, respectively.

Specific gas models are PGM's satisfying an additional condition. The ideal gas models (IGM) satisfy in addition $\mathrm{P}(\mathrm{s}) \mathrm{V}(\mathrm{s})=\mathrm{nRT}(\mathrm{s})$ for all $\mathrm{s}$ in $\mathrm{S}$, or simply $\mathrm{PV}=\mathrm{nRT}$, where $\mathrm{R}$ is the so-called ideal gas constant. For gas models with mutual attraction (GMa) there is a non-negative real (number) constant a, within a certain fixed interval, such that $\left(\mathrm{P}+\left(\mathrm{n}^{2} \mathrm{a} / \mathrm{V}^{2}\right)\right) \mathrm{V}=\mathrm{nRT}$. For gas models with non-zero volume of molecules $(\mathrm{GMb})$ there is a non-negative real constant $b$, within a certain fixed interval, such that $\mathrm{P}(\mathrm{V}-\mathrm{nb})=\mathrm{nRT}$. Finally, in the case of Van der Waals gas models (WGM) there are non-negative real constants a and $b$, within the previously mentioned two intervals, such that $\left(\mathrm{P}+\left(\mathrm{n}^{2} \mathrm{a} / \mathrm{V}^{2}\right)\right)(\mathrm{V}-\mathrm{nb})=\mathrm{nRT} .^{13}$

Note first that it is a necessary condition for con $(\mathrm{x}, \mathrm{y})(\mathrm{x}$ and $\mathrm{y}$ in PGM) that $\mathrm{x}$ and $y$ have the same set of thermal states $(\mathrm{Sx}=\mathrm{Sy})$. Note also that IGM/GMa/GMb/WGM have been defined such that they are all convex and mediating.

It is easy to check that IGM, GMa and WGM as well as IGM, GMa and WGM constitute a concretization triple: an element of WGM transforms into an element of $\mathrm{GMa} / \mathrm{GMb}$ by substituting the value 0 for $\mathrm{b}$ and $\mathrm{a}$, respectively. The resulting elements of GMa and GMb transform into elements of IGM by substituting 0 for a and $b$, respectively.

Due to the DC-Theorem, it follows that GMa and GMb are both refined closer to WGM than IGM. ${ }^{14}$ As a consequence, if WGM represented the true set of nomically

\footnotetext{
13 Note that the two factors become negligible when the volume is very large.

14 Note that GMa and GMb are mutually not comparable relative to IGM, e.g. GMb is refined not closer to GMa than IGM.
} 
possible gases, GMa and GMb would be refined closer to the truth than IGM. Finally, and most importantly, the TADC-Corollary guarantees that WGM is refined closer to the truth than IGM, assuming the heuristic hypothesis that the true set of nomically possible gases is on its turn a concretization of WGM.

\subsection{Validity research}

Scientific research is not always directed at describing the actual world or characterizing the set of nomically possible worlds. It may also primarily aim at proving interesting theorems for certain conceptual possibilities. Hamminga (1983) showed this for neo-classical economics, in particular the theory of international trade.

Let a certain domain of research and a vocabulary have been chosen, and hence a universe of conceptual possibilities $\mathbf{U}$, let $\mathbf{T}$ indicate the (unknown) subset of nomic possibilities, and let $\mathrm{R}_{\mathrm{mf}}$ indicate the (equally unknown) subset (of $\mathbf{T}$ ) of as a matter of fact realized (nomic) possibilities, possibly containing just one element, the actual possibility.

Let IT indicate an 'interesting theorem', that is some insightful claim, of which it is interesting to know whether it is true for the nomic possibilities, or at least the realized possibilities. Let VAL(IT), or simply VAL, indicate the set of conceptual possibilities for which IT can be proven. VAL is called the domain of (provable) validity of IT, and it is assumed to be not yet explicitly characterized.

A frequently occurring type of scientific progress is the following. Suppose that it was proven earlier that IT holds for M, i.e., that M is a subset of VAL. The new result is that $\mathbf{M}^{*}$, which includes $\mathrm{M}$, is also, like $\mathrm{M}$, included in VAL. Due to concentricity of the basic and refined theorylikeness notions, it follows in this case that $\mathrm{M}^{*}$ is closer to VAL than M both in the basic and the refined sense (MTLb/ MTLr(M, M*, VAL). The ultimate purpose of this type of research was to find out whether $\mathbf{T}$, or at least $\mathrm{R}_{\mathrm{mf}}$, is a subset of VAL. Of course, the larger VAL has been proven to be, as in the described case, the greater the chance, informally speaking, that $\mathrm{R}_{\mathrm{mf}}$ or even $\mathbf{T}$ are subsets of VAL. However, simply enlarging the proven domain of validity does not necessarily go in the direction of $\mathrm{R}_{\mathrm{mf}}$ and $\mathbf{T}$. For this purpose, concretization is the standard strategy.

Let it first have been shown that $\mathrm{M}$ is a subset of VAL, and later that a concretization $\mathrm{M}^{*}$ of $\mathrm{M}\left(\mathrm{CON}\left(\mathrm{M}, \mathrm{M}^{*}\right), \mathrm{M}\right.$ need not be a subset of $\left.\mathrm{M}^{*}\right)$ is also a subset of VAL. It then trivially follows that $\operatorname{MTLr}\left(\mathrm{M}, \mathrm{M} \cup \mathrm{M}^{*}\right.$, VAL). If, moreover, $\mathrm{M}^{*}$ is convex and mediating, it follows from the heuristic hypothesis that $\mathbf{M}^{*}$ is a concretization of $\mathbf{T}$ $\left(\mathrm{CON}\left(\mathrm{M}^{*}, \mathbf{T}\right)\right)$, using the DC-Theorem, that MTLr(M, $\left.\mathbf{M}^{*}, \mathbf{T}\right)$. Hence, we have proven IT for a set $\mathbf{M}^{*}$ which is more similar to $\mathbf{T}$ than $\mathbf{M}$, which increases the chance that IT holds for $\mathbf{T}$, ipso facto for $\mathrm{R}_{\mathrm{mf}}$.

A complex form of validity research concerns the case that IT is not fixed, but that realistic factors are successively accounted for. Formally, this is also a form of concretization. $\mathrm{IT}_{2}$ is called a concretization of $\mathrm{IT}_{1}$ if $\mathrm{VAL}\left(\mathrm{IT}_{2}\right)=\mathrm{VAL} 2$ is a concretization of $\operatorname{VAL}\left(\mathrm{IT}_{1}\right)=\mathrm{VAL}_{1}$.

Now suppose that $\mathrm{IT}_{1}$ is proven for $\mathrm{M}$. The relevant heuristic strategy is to look for a concretization $\mathrm{M}^{*}$ of $\mathrm{M}$ and a concretization $\mathrm{IT}_{2}$ of $\mathrm{IT}_{1}$ such that $\mathrm{IT}_{2}$ can be proven 
for $\mathbf{M}^{*}$. The heuristic hypotheses are that $\mathbf{T}$ is a concretization of $\mathbf{M}^{*}$ and that there is a concretization $\mathrm{IT}^{*}$ of $\mathrm{IT}_{2}$ such that $\mathrm{IT}^{*}$ holds for $\mathbf{T}$ and hence for $\mathrm{R}_{\mathrm{mf}}$. This makes sense because, if $\mathrm{M}^{*}$ and $\mathrm{IT}_{2}$ are convex and mediating, it not only follows that $\mathrm{M}^{*}$

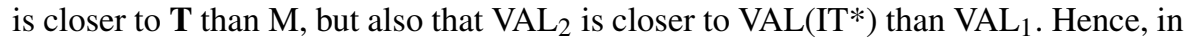
this case we are not only on the way to $\mathbf{T}$ but also to IT*.

The concretization of the theory and corresponding theorem of Modigliani and Miller concerning the capital structure of firms by Kraus and Litzenberg turns out to be a perfect example of this kind of approximation of a provable interesting truth. It is presented in (Kuipers 2000, Chapter 11).

\section{Some evaluation}

Although the refined definitions are in our view rather plausible in themselves, we like to conclude with the evaluation of the refined approach with regard to some general principles and objections that have been discussed in the literature, notably by Graham Oddie. In this section we will freely speak of the sets $\mathrm{M}$ and $\mathrm{P}$ and the theories $\mathrm{M}$ and P.

\subsection{The value of content for truths}

Let us start with the highly desirable principle of the (positive) value of content for truths (Oddie 2016), which amounts in terms of Ilkka Niiniluoto (1987, p. 230) to: among true theories truthlikeness should covary with logical strength. So, let $<\mathrm{M}^{*}$, $\mathrm{P}^{*}>$ be true and stronger than $<\mathrm{M}, \mathrm{P}>$, hence also true. That is, we assume: $\mathrm{M} \subset \mathrm{M}^{*} \subseteq \mathbf{T}$ and $\mathbf{T} \subseteq \mathrm{P}^{*} \subset \mathrm{P}$. It is easy to check that the basic definition satisfies it: $\mathbf{M}^{*} \Delta \mathbf{T} \subset \mathbf{M} \Delta \mathbf{T}$ and $\mathrm{P}^{*} \Delta \mathbf{T} \subset \mathrm{P} \Delta \mathbf{T}$. It is also easy to check that the usefulness-clauses (ii) of the refined definition (see Definition 3, Sect. 3) are empty (e.g. $\left.\mathbf{M}^{*}-(\mathbf{M} \cup \mathbf{T})=\emptyset\right)$, and hence that they are trivially satisfied by true theories, and even in both directions. Moreover, $<\mathrm{M}^{*}$, $\mathrm{P}^{*}>$ satisfies the likeness-clauses (i) relative to $<\mathrm{M}, \mathrm{P}>$. E.g. for $\mathrm{x}$ in $\mathrm{M}$, and hence in $\mathrm{M}^{*}$, and $\mathrm{z}$ in $\mathbf{T}$, if $\mathrm{r}(\mathrm{x}, \mathrm{z})$ then $\mathrm{s}(\mathrm{x}, \mathrm{x}, \mathrm{z})$ holds because structurelikeness $(\mathrm{s}(\mathrm{x}, \mathrm{y}, \mathrm{z})$ ) is supposed to be conditionally left reflexive. Hence $<\mathrm{M}^{*}, \mathrm{P}^{*}>$ is also refined at least as close to the truth as $<\mathrm{M}, \mathrm{P}>$. Finally, a simple Venn-diagrammatic representation shows that when $\mathrm{s}(\mathrm{x}, \mathrm{y}, \mathrm{z})$ is based on Euclidean distances the likeness-clauses will not be satisfied in the other direction, in which case $\left\langle\mathrm{M}^{*}, \mathrm{P}^{*}>\right.$ is definitely closer to the truth than $<\mathrm{M}, \mathrm{P}>$ in the refined sense. It is even difficult to see how $\mathrm{s}(\mathrm{x}, \mathrm{y}, \mathrm{z})$ could be defined such that this is not the case. In sum, both the basic and the refined definition satisfy the (positive) value of content for truths.

\subsection{The (dis-)value of content for falsehoods}

Regarding false theories and strength, let me first quote Oddie (2016):

"[H]ow might strength determine verisimilitude [truthlikeness] amongst false theories? There seem to be just two plausible candidates: that verisimilitude increases with increasing strength (the principle of the value of content for false- 
hoods) or that it decreases with increasing strength (the principle of the disvalue of content for falsehoods). Both proposals are at odds with attractive judgements and principles."

It is indeed also very interesting to elaborate the way in which the refined approach works out with respect to these two possible principles. Let us first note that in particular the first principle, the value of content for falsehoods, is also known as the so-called child's play objection of Pavel Tichý (Tichý 1974, p. 157, fn. 2) and Oddie (Oddie 1981), for it seems to enable truth approximation by just adding new claims to false theories. It might seem that this objection can be made at the P-side of the basic case. An analysis in terms of truth- and falsity-content focused on our particular setup of nomic theories will be very illuminating. Let theory $\mathrm{P}$ be false, hence with a non-empty falsity-content $\mathrm{cP}-\mathrm{c} \mathbf{T}=\mathbf{T}-\mathrm{P}$, with the extreme case $\mathbf{T}-\mathrm{P}=\mathbf{T}$, i.e. $\mathbf{T}$ and $\mathrm{P}$ do not overlap. Now it is easy to check that if we strengthen $\mathrm{P}$ to $\mathrm{P}^{*}\left(\mathrm{P}^{*} \subset \mathrm{P}\right)$ such that the falsity-content remains the same (the FC-constant condition), which is guaranteed in the extreme case, then the truth-content increases: $\mathrm{cP} \cap \mathrm{c} \mathbf{T} \subset \mathrm{cP}^{*} \cap \mathrm{cT}$. Hence, under the FC-constant condition, it is a child's play to come basically closer to the truth and is 'the value of content' highly plausible for false theories. Of course, not knowing $\mathbf{T}$, we can't guarantee the FC-constant condition. In other words, basic truth approximation is only a child's play when we know the nomic truth. But this is difficult to see as an objection. It will be no surprise that the refined definition keeps this property. Both refined clauses are trivially satisfied, the likeness-clause by the assumption that $\mathrm{s}(\mathrm{x}, \mathrm{y}$, z) is conditionally left symmetric, the usefulness-clause by being empty.

At the M-side, we have of course a similar situation. When we strengthen (the claim of) $\mathrm{M}$ to $\mathrm{M}^{*}\left(\mathrm{M} \subset \mathrm{M}^{*}\right)$ such that the non-empty falsity-content remains constant $\left(\emptyset \neq \mathbf{M}-\mathbf{T}=\mathrm{M}^{*}-\mathbf{T}\right)$ we increase the truth-content and hence come basically and refined closer to the truth. Again, in practice we have no control over the condition and so the child's play is idle.

There is another type of child's play that is even more interesting, in particular at the $\mathbf{M}$-side. When $\mathbf{M}$ is false $(\mathbf{M}-\mathbf{T} \neq \emptyset)$ and we weaken (the claim of) $\mathbf{M}$ to $\mathrm{M}^{\#}\left(\mathrm{M}^{\#} \subset \mathrm{M}\right)$ such that the truth-content remains constant (TC-constant condition) $\left(\mathrm{M} \cap \mathbf{T}=\mathrm{M}^{\#} \cap \mathbf{T}\right)$ the falsity-content decreases $\left(\mathrm{M}^{\#}-\mathbf{T} \subset \mathbf{M}-\mathbf{T}\right)$ and hence may even become empty. According to the basic definition such weakening is straightforward truth approximation; again a child's play assuming the non-realistic TC-constant condition. Of course, the reverse side of this is that strengthening (the claim) of M, under constant truth-content, has a negative effect on truth approximation. Hence, it illustrates the principle of the (negative value or) disvalue of content for falsehoods when TC is kept constant. At the P-side we obtain the parallel situation by assuming $\mathrm{P}$ false $(\mathrm{cP}-\mathrm{cT}=\mathbf{T}-\mathrm{P} \neq \emptyset)$ and weakening it $\left(\mathrm{P} \subset \mathrm{P}^{\#}\right)$ such that its truth-content remains constant $\left(\mathrm{cP}^{\#} \cap \mathrm{c} \mathbf{T}=\mathrm{cP} \cap \mathrm{cT}\right)$. The falsity-content will then decrease $\left(\mathbf{T}-\mathrm{P}^{\#}\right.$ $\subset \mathbf{T}-\mathrm{P}$ ) and hence basic truth approximation is obtained. Again, strengthening under this condition brings us further from the truth.

It is important to note that we may already conclude that Oddie's suggestion in the quotation that either the principle of the value of content for falsehoods or the principle of the disvalue of content for falsehoods will hold in general is mistaken. For in the 
Table $6 \mathrm{M}^{\#}=\operatorname{Mod}\left(\left(\mathrm{p}_{1} \Leftrightarrow \neg \mathrm{p}_{2}\right) \quad \& \quad \neg \mathrm{p}_{3}\right)$ is basically closer to $\mathbf{T}=\operatorname{Mod}\left(\left(\left(\mathrm{p}_{1} \mathrm{vp}_{2}\right) \Rightarrow \mathrm{p}_{3}\right)\right.$ than $\mathrm{M}=\operatorname{Mod}\left(\left(\mathrm{p}_{1} \mathrm{vp}_{2}\right) \& \neg \mathrm{p}_{3}\right)$, but $\mathbf{M}$ is refined closer to $\mathbf{T}$ than $\mathbf{M}^{\#}$

\begin{tabular}{lccclll}
\hline $\begin{array}{l}\text { Propositional } \\
\text { constituents/models }\end{array}$ & $\mathrm{p}_{1}$ & $\mathrm{p}_{2}$ & $\mathrm{p}_{3}$ & $\begin{array}{l}\mathrm{M} \text { : models of } \\
\left(\mathrm{p}_{1} \mathrm{vp}_{2}\right) \& \neg \mathrm{p}_{3}\end{array}$ & $\begin{array}{l}\mathrm{M}^{\#}: \text { models of } \\
\left(\mathrm{p}_{1} \Leftrightarrow \neg \mathrm{p}_{2}\right) \& \neg \mathrm{p}_{3}\end{array}$ & $\begin{array}{l}\text { T: models of } \\
\left(\mathrm{p}_{1} \mathrm{vp}_{2}\right) \Rightarrow \mathrm{p}_{3}\end{array}$ \\
\hline $\mathrm{s}_{1}=\mathrm{p}_{1} \& \mathrm{p}_{2} \& \mathrm{p}_{3}$ & 1 & 1 & 1 & 0 & 0 & 1 \\
$\mathrm{~s}_{2}=\neg \mathrm{p}_{1} \& \mathrm{p}_{2} \& \mathrm{p}_{3}$ & 0 & 1 & 1 & 0 & 0 & 1 \\
$\mathrm{~s}_{3}=\mathrm{p}_{1} \& \neg \mathrm{p}_{2} \& \mathrm{p}_{3}$ & 1 & 0 & 1 & 0 & 0 & 1 \\
$\mathrm{~s}_{4}=\mathrm{p}_{1} \& \mathrm{p}_{2} \& \neg \mathrm{p}_{3}$ & 1 & 1 & 0 & 1 & 0 & 0 \\
$\mathrm{~s}_{5}=\neg \mathrm{p}_{1} \& \neg \mathrm{p}_{2} \& \mathrm{p}_{3}$ & 0 & 0 & 1 & 0 & 0 & 1 \\
$\mathrm{~s}_{6}=\neg \mathrm{p}_{1} \& \mathrm{p}_{2} \& \neg \mathrm{p}_{3}$ & 0 & 1 & 0 & 1 & 1 & 0 \\
$\mathrm{~s}_{7}=\mathrm{p}_{1} \& \neg \mathrm{p}_{2} \& \neg \mathrm{p}_{3}$ & 1 & 0 & 0 & 1 & 1 & 0 \\
$\mathrm{~s}_{8}=\neg \mathrm{p}_{1} \& \neg \mathrm{p}_{2} \& \neg \mathrm{p}_{3}$ & 0 & 0 & 0 & 0 & 0 & 1 \\
\hline
\end{tabular}

basic case we have seen that the first principle holds when the falsity-content is kept constant and the second when the truth-content is kept constant.

The interesting point regarding the second principle is that this child's play is now blocked by the refined definition, and for good reasons. This is best illustrated by an example at the M-side. We might give up a wrongly included possibility, which is however more similar to a non-included nomic possibility than a remaining wrongly included possibility.Here is an example. Assume three elementary propositions $\mathrm{p}_{1}, \mathrm{p}_{2}$, $\mathrm{p}_{3}$ and let

$$
\begin{aligned}
& \mathbf{T}=\operatorname{Mod}\left(\left(\mathrm{p}_{1} \mathrm{vp}_{2}\right) \Rightarrow \mathrm{p}_{3}\right)=\left\{\mathrm{s}_{1}, \mathrm{~s}_{2}, \mathrm{~s}_{3}, \mathrm{~s}_{5}, \mathrm{~s}_{8}\right\} \\
& \mathrm{M}=\operatorname{Mod}\left(\left(\mathrm{p}_{1} \mathrm{vp}_{2}\right) \& \neg \mathrm{p}_{3}\right)=\left\{\mathrm{s}_{4}, \mathrm{~s}_{6}, \mathrm{~s}_{7}\right\} \\
& \mathbf{M}^{\#}=\operatorname{Mod}\left(\left(\mathrm{p}_{1} \Leftrightarrow \neg \mathrm{p}_{2}\right) \& \neg \mathrm{p}_{3}\right)=\left\{\mathrm{s}_{6}, \mathrm{~s}_{7}\right\}
\end{aligned}
$$

where the right side, in terms of propositional constituents, can be read of from Table 6 . We will assume the basic s-relation among constituents, see the beginning of Sect. 3 .

It is easy to check that $M^{\#}$ and $M$ are false, even such that neither $M^{\#}$ nor $M$ overlaps with $\mathbf{T}$, and that $\mathbf{M}^{\#}$ is a proper subset of $\mathbf{M}$. Hence $\mathbf{M}^{\#}$ is basically closer to $\mathbf{T}$ than M.

According to the refined definition (Definition 3, Sect. 3) we get however the reverse. The claim that $\mathbf{M}$ is refined at least as close to $\mathbf{T}$ as $\mathbf{M}^{\#}$ amounts to (simplified by neglecting relatedness, for all propositional constituents of the same elementary propositions, i.c. p, q and r, are related):

Likeness clause: $\quad \mathrm{M}_{(\mathrm{i})} \quad \forall_{\mathrm{x} \in \mathrm{M}}{ }^{\#} \forall_{\mathrm{z} \in \mathrm{T}} \exists_{\mathrm{y} \in \mathrm{M}} \mathrm{s}(\mathrm{x}, \mathrm{y}, \mathrm{z})$

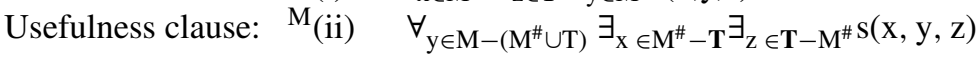

It is easy to check that this holds in the case at hand: ${ }^{M_{(i)}}$ is almost trivial due to the simplified minimal s-condition of left symmetry, $\mathrm{s}(\mathrm{x}, \mathrm{x}, \mathrm{z})$, and $\mathrm{M}^{\#}$ being a subset of $\mathrm{M}$; for $M_{(i i)}$ it is crucial, in view of the fact that $M-\left(M^{\#} \cup \mathbf{T}\right)=\left\{p_{1} \& p_{2} \& \neg p_{3}\right\}=\left\{s_{4}\right\}$, that e.g. $\mathrm{s}\left(\mathrm{s}_{6}, \mathrm{~s}_{4}, \mathrm{~s}_{1}\right)=\mathrm{s}\left(\neg \mathrm{p}_{1} \& \mathrm{p}_{2} \& \neg \mathrm{p}_{3}, \mathrm{p}_{1} \& \mathrm{p}_{2} \& \neg \mathrm{p}_{3}, \mathrm{p}_{1} \& \mathrm{p}_{2} \& \mathrm{p}_{3}\right)$ holds, where $\mathrm{s}_{6}$ is in $\mathbf{M}^{\#}-\mathbf{T}$ and $\mathrm{s}_{1}$ in $\mathbf{T}-\mathbf{M}^{\#}$.

$\mathbf{M}$ is refined even closer to $\mathbf{T}$ than $\mathbf{M}^{\#}$, for the reversed first clause

$\mathrm{M}_{(\mathrm{i}) \mathrm{rev}} \quad \forall_{\mathrm{y} \in \mathrm{M}} \forall_{\mathrm{z} \in \mathbf{T}} \exists_{\mathrm{x} \in \mathrm{M}^{\#}} \mathrm{~s}(\mathrm{x}, \mathrm{y}, \mathrm{z})$ 


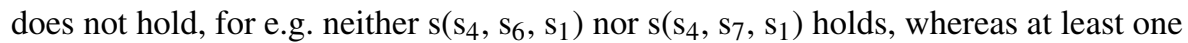
of them would be required.

Of course, at the P-side, a similar case could illustrate that weakening of a false $\mathrm{P}$ such that the truth-content remains the same results in basic truth approximation, but in general not in refined truth approximation, on the contrary. Instead of spelling this also out for nomic truth approximation, we like to turn to actual truth approximation.

\subsection{Application to actual truth approximation}

It is interesting to apply the above findings to actual truth approximation, i.e. the case that $\mathbf{T}=\{\mathbf{t}\}$ where ' $\mathbf{t}$ ' represents the actual truth. Actual truth approximation is in the first place a matter of comparing structures (see Kuipers 2000, Section 7.1), e.g. in terms of $s(x, y, t)$. But at the level of comparing sets of structures it is also possible.

Regarding the positive value of content for truths at the P-side the situation is simple. The truth- and strength condition together $\left(\mathbf{T} \subseteq \mathrm{P}^{*} \subset \mathrm{P}\right)$ entail for $\mathbf{T}=\{\mathbf{t}\}$ that $\mathbf{t} \in \mathrm{P}^{*} \subset \mathrm{P}$, from which it is easy to see that the truth-content increases and the falsitycontent remains empty, leading to basic and refined actual truth approximation. At the M-side, the condition $\mathbf{M} \subset \mathbf{M}^{*} \subseteq \mathbf{T}$ entails for $\mathbf{T}=\{\mathbf{t}\}$ the unique case $\emptyset=\mathbf{M}, \mathbf{M}^{*}=\{\mathbf{t}\}$, which is a trivial case of basic and refined actual truth approximation.

Let us now turn to the child's play of strengthening a false theory while keeping the falsity-content constant. At the $\mathrm{P}$-side, $\mathrm{P}$ being false amounts to: $\mathbf{t} \notin \mathrm{P}$. By strengthening $\mathrm{P}$ to $\mathrm{P}^{*}$ we keep this falsity-content automatically the same, viz. $\{\mathbf{t}\},\left(\mathrm{cP}-\mathrm{c}\{\mathbf{t}\}=\{\mathbf{t}\}-\mathrm{P}=\{\mathbf{t}\}=\{\mathbf{t}\}-\mathrm{P}^{*}=\mathrm{cP}^{*}-\mathrm{c}\{\mathbf{t}\}\right)$, but increase the truth-content $\left(\mathrm{cP} \cap \mathrm{c}\{\mathbf{t}\}=\mathrm{cP}-\{\mathbf{t}\} \subset \mathrm{cP} * \cap \mathrm{c}\{\mathbf{t}\}=\mathrm{cP}^{*}-\{\mathbf{t}\}\right)$. Hence, basic and refined truth approximation result. At the $\mathrm{M}$-side, the strengthening while keeping the falsity-content constant can only be done by just including $\mathbf{t}$ (i.e. $\mathbf{M}^{*}=\mathbf{M} \cup\{\mathbf{t}\}$ ), again resulting in basic and refined truth approximation. Hence, not surprisingly, also basic and refined actual truth approximation respect the principle of the value of content for falsehoods in the present setup, assuming constant falsity-constant, hence again only useful on condition of knowing the actual truth.

Remains to study the child's play of actual truth-approximation by weakening while keeping the truth-content constant. To be sure, on the M-side the case of actual truth approximation may seem at first sight somewhat weird in general as soon as $\mathrm{M}$ is not a singleton set $\{m\}$, because the claim of $M$ amounts to $M \subseteq\{t\}$, that is, in terms of 'individual claims', for all $\mathrm{m} \in \mathrm{M} \mathrm{m}=\mathbf{t}$. Hence, formally speaking, the claim is inconsistent, assuming the structures in $\mathrm{M}$ are really different. ${ }^{15}$ But it is nevertheless interesting to see what happens when we weaken a false theory $\left(M-\{t\} \neq \emptyset, M^{\#}\right.$ $\subset \mathrm{M})$ with constant truth-content $\left(\mathrm{M} \cap\{\mathbf{t}\}=\mathrm{M}^{\#} \cap\{\mathbf{t}\}\right)$, hence $\mathbf{t}$ is either in both $\mathrm{M}$ and $\mathrm{M}^{\#}$ or in neither of the two. Of course we get basic actual truth approximation. Again by way of a propositional example we will show that this is not necessarily so in the refined approach. ${ }^{16}$ Assuming two elementary propositions, $\mathrm{p}_{1}$ and $\mathrm{p}_{2}$, let

$$
\mathbf{T}=\left\{\mathrm{p}_{1} \& \mathrm{p}_{2}\right\}=\{\mathbf{t}\}
$$

\footnotetext{
15 Note that this is not so in the nomic case, because then we do not know the size of $\mathbf{T}$.

16 The example was provided to me by Gerhard Schurz and initiated in fact this whole section.
} 


$$
\begin{aligned}
& \mathrm{M}=\operatorname{Mod}\left(\neg \mathrm{p}_{1} \mathrm{v} \neg \mathrm{p}_{2}\right)=\left\{\neg \mathrm{p}_{1} \& \mathrm{p}_{2}, \neg \mathrm{p}_{1} \& \neg \mathrm{p}_{2}, \mathrm{p}_{1} \& \neg \mathrm{p}_{2}\right\}=\mathrm{M}^{\#} \cup\left\{\mathrm{p}_{1} \& \neg \mathrm{p}_{2}\right\} \\
& \mathrm{M}^{\#}=\operatorname{Mod}\left(\neg \mathrm{p}_{1}\right)=\left\{\neg \mathrm{p}_{1} \& \mathrm{p}_{2}, \neg \mathrm{p}_{1} \& \neg \mathrm{p}_{2}\right\}
\end{aligned}
$$

It is easy to check that (the claim of) $\mathrm{M}^{\#}$ is a weakening of (that of) $\mathrm{M}$, with both an empty truth content, and hence that $\mathbf{T} \Delta \mathrm{M}^{\#} \subset \mathbf{T} \Delta \mathrm{M}$, that is, $\mathbf{M}^{\#}$ is basically closer to T than $\mathrm{M}$.

According to the refined definition (again neglecting relatedness, for all propositional constituents of the same elementary propositions, i.c. $\mathrm{p}_{1}$ and $\mathrm{p}_{2}$, are related) we get however the reverse. The claim that $M$ is refined at least as close to $\mathbf{T}$ as $\mathbf{M}^{\#}$ amounts in the case of actual truth approximation to:

Likeness clause:

M(i) $\forall_{\mathrm{x} \in \mathrm{M}^{\#}} \forall_{\mathrm{z} \in \mathbf{T}} \exists_{\mathrm{y} \in \mathrm{M}} \mathrm{s}(\mathrm{x}, \mathrm{y}, \mathrm{z}) \equiv \forall_{\mathrm{x} \in \mathrm{M}^{\#}} \exists_{\mathrm{y} \in \mathrm{M}} \mathrm{s}(\mathrm{x}, \mathrm{y}, \mathrm{t})$

Usefulness clause:

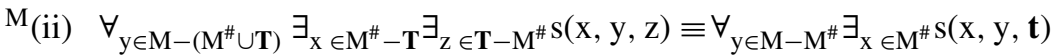

It is easy to check that this holds:

$\operatorname{Ad}^{\mathrm{M}}(\mathrm{i})$ : the two possible cases follow from the minimal s-conditions, notably s(x, $\mathrm{x}, \mathrm{z}$ ),

Ad ${ }^{M}$ (ii): for the only case $y=p_{1} \& \neg p_{2}$ we take $x=\neg p_{1} \& \neg p_{2}$, for, of course, $\mathrm{s}\left(\neg \mathrm{p}_{1} \& \neg \mathrm{p}_{2}, \mathrm{p}_{1} \& \neg \mathrm{p}_{2}, \mathbf{t}\right)$.

$\mathbf{M}$ is refined even closer to $\mathbf{T}$ than $\mathbf{M}^{\#}$, for the reversed first clause

$$
\mathrm{M}_{(\mathrm{i}) \mathrm{rev}} \quad \forall_{\mathrm{y} \in \mathrm{M}} \forall_{\mathrm{z} \in \mathbf{T}} \exists_{\mathrm{x} \in \mathrm{M}^{\#}} \mathrm{~S}(\mathrm{x}, \mathrm{y}, \mathrm{z}) \equiv \forall_{\mathrm{y} \in \mathrm{M}} \exists_{\mathrm{x} \in \mathrm{M}^{\#}} \mathrm{~s}(\mathrm{y}, \mathrm{x}, \mathbf{t})
$$

does not hold for $\mathrm{y}=\mathrm{p}_{1} \& \neg \mathrm{p}_{2}$.

Hence, the example shows that the refined account does not respect the principle of the disvalue of content for falsehoods. At the M-side, it is blocked as a general principle, for just dropping a mistaken structure is not a step forward when that structure is relatively close to the true structure compared to some other structures.

At the P-side the relevant conditions are not applicable in the case of actual truth approximation. $\mathrm{P}$ false amounts to $\{\mathbf{t}\}-\mathrm{P}^{\#} \neq \emptyset$, weakening to $\mathrm{P} \subset \mathrm{P}^{\#}$ and constant truth-content to $\mathrm{cP} \cap \mathrm{c}\{\mathbf{t}\}=c \mathrm{P}^{\#} \cap \mathrm{c}\{\mathbf{t}\}$, i.e. $\mathrm{cP}-\{\mathbf{t}\}=c \mathrm{P}^{\#}-\{\mathbf{t}\}$. Since $\mathbf{t}$ is not in $\mathrm{P}^{\#}$, hence not in $\mathrm{P}$, because $\mathrm{P} \subseteq \mathrm{P}^{\#}$, the last condition can only be satisfied by $\mathrm{P}=\mathrm{P}^{\#}$, hence not by $\mathrm{P} \subset \mathrm{P}^{\#}$.

In sum, it is possible that the refined account of nomic and actual truth approximation does not only refine the basic account in the sense that it decides cases of incomparability; it may also disagree with the basic account. ${ }^{17}$ This is plausible since, as we have seen (Sect. 3), the first clause is a strengthening and the second a weakening of the corresponding basic clauses. Hence, the question arises, which account should be preferred in a case of conflict? In my view the refined version should in general be preferred, because from the 'scientific common sense' point of view the basic account is rather naïve and coarse. However, there may be special, e.g. propositional, cases where the basic approach is to be preferred.

\footnotetext{
17 Recall that the refined definition reduces to the basic one for trivial similarity (i.e., $s(x, y, z)$ iff $x=y=z)$.
} 
Table 7 Survey of the scores of the basic and refined account regarding Oddie's principle of the (positive) value of content for truths and the principle of the (positive) value of content for falsehoods versus the principle of the (negative or) disvalue of content for falsehoods

\begin{tabular}{lllll}
\hline $\begin{array}{l}\text { The value of } \\
\text { content / } \\
\text { strengthening }\end{array}$ & $\begin{array}{l}\text { N.B. actual: } \\
\mathbf{T}=\{\mathbf{t}\}\end{array}$ & $\begin{array}{l}\text { Truth-/falsehood-and } \\
\text { strength-condition }\end{array}$ & Extra condition & $\begin{array}{l}\text { Effect for truth } \\
\text { approximation }\end{array}$ \\
\cline { 2 - 3 } & & Basic & Refined \\
\hline
\end{tabular}

For truths

$\begin{array}{lll}\text { Nomic } & \mathbf{T} \subseteq \mathrm{P}^{*} \subset \mathrm{P} & \text { Positive Positive } \\ \text { Actual } & \mathbf{t} \in \mathrm{P}^{*} \subset \mathrm{P} & \text { Positive Positive } \\ \text { Nomic } & \mathrm{M} \subset \mathrm{M}^{*} \subseteq \mathbf{T} & \text { Positive Positive } \\ \text { Actual } & \emptyset=\mathrm{M}, \mathrm{M}^{*}=\{\mathbf{t}\} & \text { Positive Positive }\end{array}$

For falsehoods, with constant falsity-content

$\begin{array}{llll}\text { Nomic } & \mathbf{T}-\mathrm{P} \neq \emptyset, \mathrm{P}^{*} \subset \mathrm{P} & \left.\mathbf{T}-\mathrm{P}=\mathbf{T}-\mathrm{P}^{* a} \mathbf{a}\right) & \begin{array}{l}\text { Positive Positive } \\ \text { Actual }\end{array} \\ \text { Nomic } & \mathbf{t} \notin \mathrm{P}, \mathrm{P}^{*} \subset \mathrm{P}\left(\Rightarrow \mathbf{t} \notin \mathrm{P}^{*}\right) & \begin{array}{l}\text { no extra condition } \\ \text { needed }\end{array} & \text { Positive Positive } \\ \text { Actual } & \mathrm{M}-\{\mathbf{t}\} \neq \emptyset, \mathrm{M} \subset \mathrm{M}^{*} & \mathbf{M}-\{\mathbf{t}\}=\mathbf{M}^{*}-\{\mathbf{t}\}^{\mathrm{b})} & \text { Positive Positive }\end{array}$

For falsehoods, with constant truth-content

\begin{tabular}{llll} 
Nomic & $\mathbf{T}-\mathrm{P} \neq \emptyset, \mathrm{P}^{*} \subset \mathrm{P}$ & $\mathrm{cP} * \mathrm{c} \mathbf{T}=\mathrm{cP} \cap \mathrm{cT}$ & Negative Blocked \\
Actual & $\{\mathbf{t}\}-\mathrm{P} \neq \emptyset, \mathrm{P}^{*} \subset \mathrm{P}$ & $\mathrm{cP} \cap \cap \mathrm{c}\{\mathbf{t}\}=\mathrm{cP} \cap \mathrm{c}\{\mathbf{t}\}^{\mathrm{c})}$ & n.a. $\quad$ n.a. \\
Nomic & $\mathrm{M}-\mathbf{T} \neq \emptyset, \mathrm{M} \subset \mathrm{M}^{*}$ & $\mathrm{M} \cap \mathbf{T}=\mathrm{M}^{*} \cap \mathbf{T}$ & Negative Blocked \\
Actual & $\mathrm{M}-\{\mathbf{t}\} \neq \emptyset, \mathrm{M} \subset \mathrm{M}^{*}$ & $\mathrm{M} \cap\{\mathbf{t}\}=\mathrm{M}^{*} \cap\{\mathbf{t}\}$ & Negative Blocked \\
\hline
\end{tabular}

Remarks: (a) guaranteed when $\mathrm{P}$ and $\mathbf{T}$ do not overlap, (b) together, the conditions can only be satisfied when $\mathbf{t}$ does not belong to $\mathrm{M}$ and $\mathrm{M}^{*}=\mathrm{M} \cup\{\mathbf{t}\}$, (c) since $\mathbf{t}$ is not in $\mathrm{P}$, hence not in $\mathrm{P}^{*}$ if $\mathrm{P}^{*} \subseteq \mathrm{P}$, this condition can only be satisfied by $\mathrm{P}^{*}=\mathrm{P}$

Table 7 summarizes the results of Sects. 6.1, 6.2 and 6.3. It is important to note that, in order to get strengthening as the uniform action in the table, in the last main row (dealing with strengthening of falsehoods with constant truth-content) $\mathrm{P}^{*}$ and $\mathrm{M}^{*}$ are the stronger versions of $\mathrm{P}$ and $\mathrm{M}$, respectively, whereas in the text $\mathrm{P}^{\#}$ and $\mathrm{M}^{\#}$ were the weaker versions.

\subsection{Some other principles}

Ilkka Niiniluoto rightly conjectured (personal communication) that the refined definition satisfies the qualitative version of Graham Oddie's (2016) 'uniform distance principle', that is, assuming propositional constituents $\mathrm{x}$ and $\mathrm{y}$ : "if $\mathrm{x}$ and $\mathrm{y}$ are equally distant from $\mathbf{t}$, then also their disjunction $\mathrm{x} v \mathrm{y}$ is at the same distance." Qualitatively it amounts to the claim that $\mathrm{s}(\mathrm{x}, \mathrm{y}, \mathrm{t})$ and $\mathrm{s}(\mathrm{y}, \mathrm{x}, \mathrm{t})$ together imply (using the minimal s-condition s(x, x, z)) that, e.g. $\{\mathrm{x}, \mathrm{y}\}$ is refined equally close to $\{\mathbf{t}\}$ as $\{\mathrm{x}\}$ and $\{\mathrm{y}\}$, respectively. Assuming general relatedness, ${ }^{18}$ it also holds in general, and hence

\footnotetext{
18 For all $\mathrm{x}$ and $\mathrm{z}$ in $\mathrm{Ur}(\mathrm{x}, \mathrm{z})$, that is, for all $\mathrm{x}$ and $\mathrm{z}$ in $\mathrm{U}$ there is $\mathrm{y}$ in $\mathrm{U}$ such that $\mathrm{s}(\mathrm{x}, \mathrm{y}, \mathrm{z})$. Hence, the in Sect. 6.3 given general versions of $\mathrm{M}_{(\mathrm{i})}$ and $\mathrm{M}_{(\mathrm{ii})}$ apply.
} 
Table 8 Survey of the principles: uniform distance, Pareto, and difference

\begin{tabular}{|c|c|c|c|c|c|}
\hline Principle & & Condition & Consequence & Basic & Refined \\
\hline \multirow{2}{*}{$\begin{array}{l}\text { Uniform } \\
\text { distance }\end{array}$} & Actual & $\mathrm{s}(\mathrm{x}, \mathrm{y}, \mathbf{t}) \& \mathrm{~s}(\mathrm{y}, \mathrm{x}, \mathbf{t})$ & $\{x, y\}$ ect $\{\mathbf{t}\}$ as $\{x\} /\{y\}$ & Trivial & Yes \\
\hline & Nomic & $\mathrm{M}$ ect $\mathbf{T}$ as $\mathbf{M}^{*}$ & $\mathrm{M} \cup \mathrm{M}^{*}$ ect $\mathbf{T}$ as $\mathrm{M} / \mathrm{M}^{*}$ & Trivial & Yes \\
\hline \multirow[t]{2}{*}{ Pareto } & Actual & $\mathrm{s}(\mathrm{x}, \mathrm{y}, \mathbf{t})$ & $\mathrm{M}^{\mathrm{x} / \mathrm{y}}$ lct $\{\mathbf{t}\}$ as $\mathrm{M}$ & Trivial & Yes \\
\hline & Nomic & for all $\mathrm{z} \in \mathbf{T} \mathrm{s}(\mathrm{x}, \mathrm{y}, \mathrm{z})$ & $\mathrm{M}^{\mathrm{x} / \mathrm{y}}$ lct $\mathbf{T}$ as $\mathrm{M}$ & Trivial & Yes \\
\hline \multirow[t]{2}{*}{ Difference } & Actual & $\mathrm{s}(\mathrm{x}, \mathrm{y}, \mathbf{t})$ and/or $\mathrm{s}(\mathrm{y}, \mathrm{x}, \mathbf{t})$ & $\begin{array}{l}\text { iff } \mathrm{M}^{\mathrm{x} / \mathrm{y}} \text { lct }\{\mathbf{t}\} \text { as } \mathrm{M} \\
\text { and/or } \mathrm{M} \text { lct }\{\mathbf{t}\} \text { as } \mathrm{M}^{\mathrm{x} / \mathrm{y}}\end{array}$ & Trivial & Yes \\
\hline & Nomic & $\begin{array}{l}\text { for all } z \in \mathbf{T} s(\mathrm{x}, \mathrm{y}, \mathrm{z}) \text { and/or } \\
\quad \text { for all } \mathrm{z} \in \mathbf{T} \mathrm{s}(\mathrm{y}, \mathrm{x}, \mathrm{z})\end{array}$ & $\begin{array}{l}\text { iff } \mathrm{M}^{\mathrm{x} / \mathrm{y}} \text { lct } \mathbf{T} \text { as } \mathrm{M} \text { and/or } \\
\mathrm{M} \text { lct } \mathbf{T} \text { as } \mathrm{M}^{\mathrm{x} / \mathrm{y}}\end{array}$ & Trivial & Yes \\
\hline
\end{tabular}

ect equally close to, lct at least as close to

NB: the used minimal s-conditions are suppressed

in nomic cases, for e.g. on the $\mathrm{M}$-side: if $\mathrm{M}$ and $\mathrm{M}^{*}$ are refined equally close to $\mathbf{T}$, then $\mathrm{M} \cup \mathrm{M}^{*}$ is as well. Again, $\mathrm{s}(\mathrm{x}, \mathrm{x}, \mathrm{z})$ and $\mathrm{s}(\mathrm{x}, \mathrm{z}, \mathrm{z})$ are crucial. For this kind of reasons I have proposed in debate with Thomas Mormann (see Kuipers 2000, p. 256) the strong boundary condition for 'refined closer to' that the size of $\mathrm{M}^{*}$ should be between that of $\mathbf{M}$ and $\mathbf{T}$. This is never satisfied by $\mathbf{M} \cup \mathrm{M}^{*}$ when $\mathbf{T}=\{\mathbf{t}\}$. I have also considered there to liberate the condition to: the size of $\mathrm{M}^{*}$ should be between that of $M \cap \mathbf{T}$ and $M \cup \mathbf{T}$. However, this would not prevent the first case: $M=\{x\}$, $\mathbf{M}^{*}=\{\mathrm{y}\}, \mathbf{T}=\{\mathbf{t}\}$, as is easy to check. Instead of seeing this as a problem, one might as well agree with Oddie's principle, with the consequence that no further condition is needed.

It is interesting to check whether the definition of 'refined closer to' satisfies the other two principles proposed by Oddie, at least if we assume general relatedness. The 'Pareto principle' reads (in adapted symbols): if $\mathrm{y}$ is at least as close to the actual world $(t)$ as $x$ is, i.e. $s(x, y, t)$, then the result of substitution of $y$ for $x$ in $M$, i.e. $(M \cup\{y\})-\{x\}=\operatorname{def} M^{x / y}$, is at least as close to the truth as $M$ is. It is easy to check, using $\mathrm{s}(\mathrm{x}, \mathrm{x}, \mathrm{t})$, that this principle also holds in general, and hence in nomic cases: if $\mathrm{y}$ is refined at least as close to all $\mathrm{z}$ in $\mathbf{T}$ as $\mathrm{x}$ is, i.e. $\mathrm{s}(\mathrm{x}, \mathrm{y}, \mathrm{z})$, then $\mathrm{M}^{\mathrm{x} / \mathrm{y}}$ is at least as close to $\mathbf{T}$ as $\mathbf{M}$ is. To be sure, the condition is in a qualitative setting rather strong, but quantitatively (in terms of distances) not at all.

Finally, Oddie submits the 'difference principle', which is typically quantitative (again in adapted symbols): the difference in closeness to the truth $\{\mathbf{t}\}$ of $\mathrm{M}$ and $\mathrm{M}^{\mathrm{x} / \mathrm{y}}$ is some function or other of at most three factors: the distance of $\mathrm{x}$ from the actual world $\mathbf{t}$, the distance of $\mathrm{y}$ from the actual world, and the size of $\mathrm{M}$. In a qualitative reading it amounts to the claim that the question whether $\mathrm{M}^{\mathrm{x} / \mathrm{y}}$ is at least as close to $\{\mathbf{t}\}$ as $\mathrm{M}$, and/or the other way around, or whether they are incomparable, only depends on whether $\mathrm{s}(\mathrm{x}, \mathrm{y}, \mathbf{t})$ or $\mathrm{s}(\mathrm{y}, \mathrm{x}, \mathbf{t})$ holds, respectively. It is easy to check that this holds as well. The general version, hence including nomic cases, also holds. It amounts to: the question whether $\mathrm{M}^{\mathrm{x} / \mathrm{y}}$ is refined at least as close to $\mathbf{T}$ as $\mathrm{M}$, and/or the other way around, or whether they are incomparable, only depends on whether either $\mathrm{s}(\mathrm{x}, \mathrm{y}, \mathrm{z})$ or $\mathrm{s}(\mathrm{y}, \mathrm{x}, \mathrm{z})$ holds for all $\mathrm{z}$ in $\mathbf{T}$. 
Table 8 summarizes the principles dealt with in the present subsection. That they trivially hold in the basic case is easy to check in view of the fact that the refined definitions reduce to the basic ones when $s(x, y, z)$ is trivial $(s(x, y, z)$ iff $x=y=z)$.

It is just a matter of tedious checking that all three general principles also hold if relatedness is taken into account. Regarding the P-side, in view of the nature of the principles and the 'mirror-symmetric' correspondence between the two sides, they hold here as well.

In sum, on the basis of this section we may conclude that the refined approach deals in a sophisticated way with a number of principles and objections that have been discussed in the literature.

Acknowledgements I like to thank Ilkka Niiniluoto, Gerhard Schurz, and two anonymous referees for their challenging questions and remarks.

Open Access This article is distributed under the terms of the Creative Commons Attribution 4.0 International License (http://creativecommons.org/licenses/by/4.0/), which permits unrestricted use, distribution, and reproduction in any medium, provided you give appropriate credit to the original author(s) and the source, provide a link to the Creative Commons license, and indicate if changes were made.

\section{References}

Cevolani, G., Crupi, V., \& Festa, R. (2011). Verisimilitude and belief change for conjunctive theories. Erkenntnis, 75(2), 183-202.

Hamminga, B. (1983). Neoclassical theory structure and theory development. Berlin: Springer.

Krajewski, W. (1977). Correspondence principle and growth of science. Dordrecht: Reidel.

Kuipers, T. (1987). A structuralist approach to truthlikeness. In T. Kuipers (Ed.), What is closer-to-thetruth? A parade of approaches to truthlikeness. Poznan studies in the philosophy of the sciences and the humanities (Vol. 10, pp. 79-99). Amsterdam: Rodopi.

Kuipers, T. Book manuscript. Nomic truth approximation revisited. To appear in the Synthese library.

Kuipers, T. (2000). From instrumentalism to constructive realism. On some relations between confirmation, empirical progress, and truth approximation. Synthese library 287. Dordrecht: Kluwer Academic Publishers.

Kuipers, T. (2016). Models, postulates, and generalized nomic truth approximation. Synthese, 193(10), 3057-3077. https://doi.org/10.1007/s11229-015-0916-9.

Kuipers, T. (2017). Quantitative nomic truth approximation by revising models and postulates. In M. Massimi, J. W. Romeijn, \& G. Schurz (Eds.), European studies in philosophy of science, EPSA15 selected papers (pp. 309-320). Dordrecht: Springer.

Niiniluoto, I. (1987). Truthlikeness. Synthese library 185. Dordrecht: Reidel.

Northcott, R. (2013). Verisimilitude: a causal approach. Synthese, 190(9), 1471-1488.

Nowak, L. (1980). The structure of idealization. Synthese library 139. Dordrecht: Reidel.

Oddie, G. (1981). Verisimilitude reviewed. The British Journal for the Philosophy of Science, 32, 237-265.

Oddie, G. (2016). Truthlikeness. In E. N. Zalta (Ed.), The stanford encyclopedia of philosophy (Winter 2016 edition). https://plato.stanford.edu/archives/win2016/entries/truthlikeness/.

Tichý, P. (1974). On Popper's definition of verisimilitude. The British Journal for the Philosophy of Science, $25,155-160$. 